\title{
$1 \quad$ Paraburkholderia edwinii protects Aspergillus sp. from phenazines by acting as a toxin sponge
}

2 Kurt M. Dahlstrom ${ }^{1}$, Dianne K. Newman ${ }^{1,2}$

3

$4 \quad{ }^{1}$ Division of Biology and Biological Engineering and ${ }^{2}$ Division of Geological and Planetary Sciences,

5 California Institute of Technology, Pasadena, CA, USA

6

7

8

9 Correspondence: Dianne K. Newman

10

11

12

13

14

15

16

17

18

19

20 21 strategy, analyzed data, and wrote the paper.

22

23 This PDF file includes:

24

25

ORCID: Kurt Dahlstrom,0000-0001-6590-6020 ; Dianne Newman, 0000-0003-1647-1918.

Keywords: phenazines, bacteria, fungi, protective partnership, microbial interactions, inter-kingdom

Author Contributions: K.M.D. performed the experiments. K.M.D and D.K.N. designed the research

Main text, Figures 1 to 6

Supplemental Figures S1 to S4

Supplemental Tables S1 \& S2 


\section{7}

\section{Summary}

Many environmentally and clinically important fungi are sensitive to toxic, bacterially-produced, redox-active molecules called phenazines. Despite being vulnerable to phenazine-assault, fungi inhabit microbial communities that contain phenazine producers. Because many fungi cannot withstand phenazine challenge, but some bacterial species can, we hypothesized that bacterial partners may protect fungi in phenazine-replete environments. In the first soil sample we collected, we co-isolated several such physically associated pairings. We discovered the novel species Paraburkholderia edwinii and demonstrated it can protect a co-isolated Aspergillus species from phenazine-1-carboxylic acid (PCA) by sequestering it, acting as a toxin sponge; in turn, it also gains protection. When challenged with PCA, $P$. edwinii changes its morphology, forming aggregates within the growing fungal colony. Further, the fungal partner triggers $P$. edwinii to sequester PCA and maintains conditions that limit PCA toxicity by promoting an anoxic and highly reducing environment. A mutagenic screen revealed this program depends on the stress-inducible transcriptional repressor HrcA. We show that one relevant stressor in response to PCA challenge is fungal acidification and that acid stress causes $P$. edwinii to behave as though the fungus were present. Finally, we reveal this phenomenon as widespread among Paraburkholderia with moderate specificity among bacterial and fungal partners, including plant and human pathogens. Our discovery suggests a common mechanism by which fungi can gain access to phenazine-replete environments, and provides a tractable model system for its study. These results have implications for how rhizosphere microbial communities as well as plant and human infection sites are policed for fungal membership. 


\section{Introduction}

The presence or absence of particular fungal species in host-associated microbial communities plays a central role in human and plant health, crop yield, and climate change ${ }^{1-3}$. However, we lack an understanding of how key fungal species are integrated into these communities in the face of rampant chemical warfare. It has long been known that the soil is home to diverse microbes that produce natural products with antibiotic activity. Important amongst these are phenazines, redox active compounds that can restrict fungal growth and have been shown to be responsible for excluding fungi from agriculturally important microbial communities ${ }^{4,5}$. A recent metagenomic study revealed that phenazine biosynthesis capacity is widespread in agricultural soils and crop microbiomes ${ }^{6}$. Given that drier soils are also associated with higher rates of phenazine producers colonizing wheat, this suggests that soil fungi may need to contend with higher concentrations of phenazines as the climate shifts ${ }^{7,8}$. Paradoxically, many fungi that are sensitive to phenazines are routinely found living in close proximity to phenazine-producing bacteria, including pathogenic fungi in the lungs of cystic fibrosis patients, beneficial and phytopathogenic fungi in the rhizosphere, and in oceanic environments including coral ${ }^{9-12}$. This pattern of co-habitation indicates there may be a general way fungi are screened for membership in microbial communities that produce phenazines that holds broad relevance. We set out to identify such a putative screening mechanism, a necessary step towards the goal of manipulating these microbial communities for human benefit.

Our drive to understand how particular fungi are incorporated or rejected from a microbial community is motivated by the large impact fungal composition can have on the outcome for human and plant health. Fungi in complex polymicrobial infections act as markers of disease severity, particularly in the lungs of patients with cystic fibrosis ${ }^{13}$. In this environment, Aspergillus fumigatus and Candida albicans are two opportunistic fungal pathogens that are susceptible to phenazines, yet are routinely isolated from patients who are co-infected with the prolific phenazine producing bacterium Pseudomonas aeruginosa ${ }^{9,10}$. Likewise, fungi play prominent roles in the rhizosphere, where they can help the host 
plants acquire nutrients and water as well as withstand stress and pathogens ${ }^{14,15}$; plant-growth promoting fungi such as Trichoderma and Penicillium species are often found in rhizospheres containing phenazine producing bacteria, yet their growth is inhibited by phenazines ${ }^{11,16}$. Conversely, the ability of phytopathogenic fungi to enter the rhizosphere is of interest due to fungi being responsible for a third of all lost crops annually ${ }^{17}$. This is despite phenazines being credited as a primary factor in stopping a

83 variety of fungal phytopathogens from infecting food crops, including pseudomonads that can suppress

84 Gaeumannomyces graminis var. tritici and Fusarium oxysporum $\mathrm{f}$ sp. radicis-lycopersici, two fungal

85 pathogens of tomato and wheat, respectively ${ }^{4,5}$. Finally, plant associated fungi known as mycorrhizae play an outsized role in carbon sequestration: mycorrhizae-associated vegetation sequester approximately 350 gigatons of carbon a year compared to 29 gigatons stored by nonmycorrhizae-associated vegetation ${ }^{3}$. Notably, phenazine producers are found in diverse environments beyond food crops, including in forests and grasslands, thus pointing to another niche of consequence where fungi must navigate phenazine assault ${ }^{6}$.

How do fungi maintain an active presence in microbial communities where they run the risk of encountering phenazines? Recognizing that some soil bacteria can tolerate phenazines well ${ }^{18-20}$, we hypothesized that one mechanism by which fungi might gain navigate such hostile environments is through association with a protective bacterial partner. Precedent for such relationships exists. For example, members of the Burkholderiaceae family form associations with fungi. Trichoderma asperellum is a biocontrol fungus that suppresses the wheat pathogen Fusarium oxysporum. Paraburkholderia terrae

97 associates with the mycelium of $T$. asperellum and can be induced to migrate in the direction of mycellial 98 growth, as well as promote fungal growth in the presence of crude supernatant derived from antagonistic 99 bacteria ${ }^{21}$. However, this family of bacteria can also empower pathogenic fungi. Rhizopus microsporus 100 is a necrotic plant pathogen of rice. The primary toxin it secretes that is required for infection is actually produced by the intracellular bacterium Paraburkholderia rhizoxinica that resides inside the fungal cells 
P. fungorum, found isolated with the white-rot fungus Phanerochaete chrysosporium $^{23}$. While the

104 roles each of these bacteria play for their host fungus may differ, fungal association with bacteria of

105 this family is well established.

In addition to these isolated examples, data from a recent metagenomic survey of soil microbes across many climate conditions support the notion that cooperation with bacteria might underpin fungal ecological success ${ }^{24}$. Specifically, this study found that the presence of bacterially-derived genes regulating antibiotic tolerance were correlated with fungal biomass in the community. Although this cooccurrence was suggested to indicate inter-domain antagonism, where bacterial groups use these genes to

111 defend themselves against fungally-produced antibiotics, an alternative and non-mutually exclusive

112 explanation may be that these bacterial stress response genes help fungi navigate an otherwise

113 inhospitable environment. Given that fungi can be excluded from microbial communities by phenazine-

114 producing bacteria, it stands to reason other phenazine resistant bacteria in the community that associate 115 with fungi may have the power to affirm their presence. Because the number of environments where 116 susceptible fungi are found living in proximity to phenazine producers is likely to be high, we reasoned 117 that finding an example of such a hypothetical protective association could be of great value in understanding the recruitment versus repression of fungi in microbial communities containing phenazine 119 producers. 


\section{Results}

Isolation of protective bacterial partner and physically associated fungus.

To identify fungi that resist phenazine assault with protective bacterial partners, we sampled topsoil from the base of a blood orange citrus tree outside of the Beckman Institute on the Caltech campus. We chose this site because soil represents an easily accessible and broad niche containing many microbial species and because we had isolated a strain of Mycobacterium from this same plot that can degrade phenazines, suggesting the presence of bacteria capable of producing and interacting with these molecules ${ }^{19}$.

We collected the top three centimeters of soil from this site, and developed a protocol to find strong bacterial-fungal pairs. We washed and sonicated $100 \mathrm{mg}$ to separate microbes that were not strongly associated with one another, thereby enriching for strongly adherent partners (Fig. 1A). To select

141 a first fungal culture, the washed samples were diluted to extinction and plated on potato dextrose agar.

142 Fungal colonies that grew after approximately three days were screened for the presence of bacteria via

143 PCR amplification of the $16 \mathrm{~S}$ rDNA region. Fungal/bacterial pairings were then challenged with $300 \mu \mathrm{M}$

144 phenazine-1-carboxylic acid (PCA). We used PCA because it is the biosynthetic starting product for 145 modification into more specialized phenazine types and is known to play important roles in excluding 146 fungal pathogens from wheat rhizosphere communities ${ }^{5}$. Co-colonies that were able to grow when 147 challenged with PCA were repeatedly sub-cultured to isolate the partner bacterium, while the fungus was 148 re-plated in the absence of PCA with bacteriocidal antibiotics to cure it of the bacterium. Isolated fungi 149 and bacteria were retreated with PCA to check phenazine-sensitivity and tolerance, respectively, and 150 susceptible fungi were then supplemented with their co-isolated bacterium in the presence of PCA to 151 confirm that the partner bacterium conferred phenazine tolerance.

152 Using this process we uncovered three fungal-bacterial partnerships. Genus-level identification 153 was performed with ITS and 16S rDNA sequencing, respectively. Two Paraburkholderia isolates were 
found protecting an Aspergillus and a Lecythophora isolate. A Luteibacter species also provided

protection to a second Aspergillus isolate (Fig. S1A). In each case, the fungal growth was negatively impacted when challenged with PCA alone, but was restored to varying degrees when supplemented with its natively co-isolated bacterial partner. Of these three co-isolates, we selected the ParaburkholderiaAspergillus pairing for further analysis due to the dramatic level of protection the bacterium provided the fungus, as well as the radical morphological change the bacterium underwent as it formed spherical aggregates within the fungal colony when the two were challenged with PCA (Fig. 1B). Moreover, while the Aspergillus species is sensitive to PCA and $P$. edwinii resists its toxic effects, $P$. edwinii is still vulnerable to engulfment by the PCA producer P. fluorescens, but not to a strain that cannot make PCA, suggesting a mutual benefit (Fig. 1B). Finally, this pairing was attractive because previous reports of

Burkholderiaceae family members being isolated with fungi ${ }^{21,25}$ suggested that such associations may be

\section{P. edwinii protects its fungal partner from phenazine assault}

We next sought to characterize the range of the bacterium's ability to protect its partner fungus

174 phenazine challenge intended to identify bacterial partners with a robust protection phenotype. The

175 advantage of using a high concentration of PCA in our laboratory experiments is that it may better mimic

176 local gradients of PCA that exist within rhizosphere microbial communities that likely exceed bulk

177 measurements.

178 To determine whether P. edwinii can protect Aspergillus against actual phenazine-producers in 179 addition to purified PCA, we tested the response in the presence of different phenazine-producing 
Pseudomonads. Aspergillus was plated adjacent to Pseudomonas fluorescens, Pseudomonas

chlororaphis, Pseudomonas chlororaphis sub-species aureofaciens, and Paraburkholderia phenazinium.

182 The primary phenazine product made by these species under are growth conditions is PCA, phenazine-1-

183 carboxamide (PCN), 2-hydroxy-phenazine, and iodinin, respectively. When grown close to one another,

184 each phenazine producing bacterium impeded Aspergillus growth (Fig. 1C). However, when the fungus

185 was supplemented with $P$. edwinii, growth was partially restored. Intriguingly, bacterial aggregates again

186 formed within the co-colonies proximal to phenazine producers, suggesting this morphological phenotype

187 reflected a general protective response (Fig. 1C). Finally, to verify that these responses were specifically

188 due to phenazine assault, mutants of Pseudomonas fluorescens and Pseudomonas chlororaphis were

189 obtained that could not make phenazines ${ }^{27}$. While the WT strains were capable of suppressing fungal

190 growth, the fungus grew unimpeded in proximity of the non-phenazine producing mutants (Fig. S1B),

confirming that the protection provided by $P$. edwinii is specific to phenazine assault and can occur in a

mixed microbial system.

\section{P. edwinii undergoes a morphological shift in response to phenazine-induced fungal stress.}

To understand how $P$. edwinii responds to its partner fungus during phenazine assault, we imaged

the bacterium inside the co-colony. While a ring of what appeared to be one or two dozen bacterial aggregates formed on the co-colony surface, it remained possible these were fungal structures. To distinguish between these possibilities, we adapted a tissue clearing technique developed in our lab termed Microbial identification after PASSIVE Clarity Technique (MiPACT) to render the fungal tissue

201 transparent (see Materials and Methods). This allowed us to visualize bacteria within the fungal structure 202 using in situ fluorescence detection of $16 \mathrm{~S}$ rRNA with the hybridization chain reaction (HCR) ${ }^{28}$.

203 Because the exterior of the colonies showed putative bacterial aggregates within the center, we

204 hypothesized that may be where the bacteria were concentrated. We first imaged the outer $2 / 3$ of the 205 colonies. In the control, whole-colony samples untreated with PCA, P. edwinii was found concentrating 
near the tips of the outwardly-growing mycelium, with relatively low amounts of bacteria found further inward among older mycelial growth. The propensity of $P$. edwinii to track with the mycelial edge in the untreated samples is in agreement with reports suggesting other Paraburkholderia are capable of identifying the growing edge of expanding fungi ${ }^{21}$. Conversely, in the PCA treated sample, this population of bacteria was largely absent (Fig. 2).

To gage whether a lack of bacteria among the outer mycelium in the PCA treated samples was

212 due to bacterial aggregation, we imaged the center of each co-colony. In untreated samples, bacteria were

213 mixed homogenously throughout the fungal mass without identifiable structure or patterning (Fig. 2). One

214 exception to this observation was an apparent transition zone between the bacterially rich inner co-colony

215 and more sparely populated outer co-colony. This transition zone, or ring, comprised more densely

216 packed bacteria, but the region lacked further organization (Fig. S2). In the PCA treated sample, the

217 center of the co-colony contained clear spherical structures that lit up with the eubacterial HCR probes

218 (Fig. 2). These $P$. edwinii aggregates ranged from 50 to $100 \mu \mathrm{m}$ in diameter and were ubiquitous

219 throughout the colony center, indicating that the visible bacterial aggregates on the surface of the co-

220 colony were only a fraction of those being formed. The PCA treated co-colony also had a transition ring

221 structure between the bacterially populated center and unpopulated outer colony. In this case, however,

222 the ring contained more clearly defined aggregates of bacteria, corresponding to the region that produced

223 aggregates visible to the naked eye (Fig. S2). These results reveal that $P$. edwinii forms bacterial

224 aggregates inside and in the center of the fungal colony when challenged with PCA.

\section{$226 \quad P$. edwinii acts as a toxin sponge}

How does P. edwinii offer resistance from phenazine assault to its partner fungus? Possible

229 mechanisms included phenazine degradation, sequestration, and/or detoxification. We first tested 
231 liquid cultures spiked with $300 \mu \mathrm{M}$ PCA either alone or in the presence of the Aspergillus species, in case 232 a fungal signal was necessary to trigger degradation of PCA. In no condition was PCA degraded (Fig.

233 S3). The lack of degradation suggested that bacterial aggregate formation might instead reflect a PCA 234 sequestration and detoxification response, which we proceeded to test.

Because the bacterial aggregates are too small to probe or manipulate individually, we modified our experimental set up to grow $P$. edwinii directly next to its Aspergillus partner in the presence of PCA

237 to generate bacterial auto-aggregation in the form of a colony. To verify the protection phenotype is still

238 responsive in this assay, we grew the two organisms next to each other in the presence and absence of

239 PCA. Growing P. edwinii and the Aspergillus species at a distance in the presence of PCA resulted in

240 severely stunted fungal growth, however the fungus was able to grow toward $P$. edwinii when plated

241 adjacently (Fig. 3A). Intriguingly, the bacterial colony developed a deep yellow hue in the PCA treated

242 condition, but only did so in the presence of the fungus. PCA is a largely colorless molecule when

243 exposed to oxygen, but in the reduced state turns yellow. We used LC-MS to determine whether this

244 yellow pigment was PCA and its presence was confirmed in the bacterial sample grown next to the fungus (Fig. 3B). We detected a smaller amount of PCA in the colonies of P. edwinii grown alone in the presence of PCA than in the presence of PCA and the fungus, suggesting that while PCA sequestration may be an intrinsic trait of the bacterium, sequestration is stimulated by the fungal partner (Fig. 3C).

Having confirmed the presence of PCA within the bacterial colonies, we next wanted to assess its redox state. Previously, we had been measuring PCA sequestered from an agar plate where most of the molecule would be expected to be oxidized due to atmospheric oxygen. A better comparator for the

251 fraction of reduced PCA found within a $P$. edwinii colony would therefore be another bacterial colony

252 containing PCA, but one that was not employing a protection response involving PCA detoxification. To

253 this end, we grew P. edwinii and the Aspergillus species adjacent to the phenazine producer $P$.

254 fluorescens. PCA is the sole phenazine produced by P. fluorescens. Before the bacterial colonies were

255 harvested, the plates were transferred to an anaerobic chamber to minimize the atmospheric oxidation of 
$\mathrm{nm}$, which allowed us to determine the fraction of the PCA in the reduced state. Fluorescent emission spectra were collected in the anaerobic chamber, which revealed the phenazine-producing $P$. fluorescens colony biofilm to contain approximately $10 \%$ of its PCA in the reduced state whereas P. edwinii colonies maintained approximately a third of the PCA it sequestered in the reduced state. This result demonstrated that $P$. edwinii colony aggregates reduce PCA (Fig. 3D).

\section{HrcA is a regulator of the protection response in $P$. edwinii}

Given that PCA sequestration in P. edwinii is stimulated by its partner fungus, we aimed to discover how $P$. edwinii sensed and responded to its partner. We developed genetic tools to manipulate $P$. edwinii to screen for mutants altered in their ability to protect the fungus from PCA. Because P. edwinii is a novel soil isolate, we sequenced its genome using Illumina and PACBio technologies. Two closed

277 edwinii. Mutants were screened with the Aspergillus species on PCA, and mutants that produced an

278 atypical morphology had their transposons mapped to the inserted gene (Supplementary Table 1). $P$.

279 edwinii mutants were identified that were either less or more protective of the partner fungus. Generally,

280 more bacterial aggregation was associated with more fungal protection and vice versa (Fig. 4A). We

281 focused on a mutant with a transposon insertion in the stress inducible transcriptional repressor $h r c A$, due 
disruption of this gene and was not caused by polar effects or secondary mutations elsewhere in the

genome, we made an in-frame deletion of $h r c A$. The deletion mutant phenocopied the transposon mutant, showing enhanced bacterial aggregation and fungal growth when challenged with PCA (Fig. 4B, C). the $\triangle h r c A$ mutant promote fungal growth beyond the wild type strain during PCA challenge, but the extra-large bacterial aggregates characterizing this mutant appeared to form even in the absence of PCA, suggesting this mutant constitutively turned on the protection program (Fig. S4A). the stress response to heat shock, and deletion of $h r c A$ in $B$. subtilis results in cells that can adapt and grow more rapidly under conditions of heat stress ${ }^{30}$. By analogy, we wondered whether the removal of hrcA in $P$. edwinii might permit larger aggregate formation due to a similar growth advantage in the presence of PCA. To test this, we grew WT and $\Delta h r c A$ strains as co-colonies with the Aspergillus species in the presence or absence of PCA. Co-colonies were homogenized after 48 hours and bacterial CFUs were plated on potato dextrose agar containing nystatin to suppress fungal growth. The $\Delta h c r A$ strain showed an approximately 2-fold increase in CFUs compared to the WT per co-colony in both the PCA treated and untreated conditions (Fig. 4D). Not only did the $\Delta h c r A$ mutant grow better than the WT in the presence of PCA, it was better at sequestering PCA; as before, its ability to sequester PCA was stimulated in the presence of the fungus (Fig. 4E). Because the amount of PCA sequestered is normalized by the dry weight of the collected biomass, a growth advantage alone is not sufficient to explain these results. Though bacterial aggregation in the $\Delta h c r A$ mutant was enhanced relative to the $\mathrm{WT}$, it failed to form a biofilm using the crystal violet assay ${ }^{31}$ — possibly linked to a swimming motility defect we uncovered using a swim assay(Fig. 4F). These results suggest that the protection/aggregation phenotype relies on a different developmental program from that involved in classical biofilm development. 
Phenazines exert toxic effects on diverse cell types through a variety of mechanisms including

generating reactive oxygen species and destabilizing the electron transport chain of the target cell

311 dependent upon the ability of the phenazine to cycle its redox state in the presence of oxygen ${ }^{13,32-37}$. It

312 may therefore seem paradoxical that the Aspergillus species achieves protection against PCA by

313 promoting concentration of PCA within its co-culture. Given that $P$. edwinii colonies are enriched in

314 reduced PCA relative to the phenazine producer, P. fluorescens (Fig. 3D), we hypothesized that a solution

315 to this paradox might come from limiting oxygen by maintaining a reducing environment within the

316 bacterial aggregates. We used oxygen and redox microelectrodes to test this hypothesis.

Because the co-colony bacterial aggregates are of a similar size as the width of our

microelectrode tips ( $25-100 \mu \mathrm{m}$ ), puncture when probed, and are invisible from the outside of the coPCA, the bacterial colony became taller and encased in an apparent layer of polysaccharide (Fig. S4B).

326 Oxygen levels in this thicker colony dropped slowly through the outer layer, disappearing at

327 approximately $180 \mu \mathrm{m}$. Oxygen was again detected at $380 \mu \mathrm{m}$, indicating a larger anoxic volume within

328 the colony compared to the untreated colony. When grown next to its partner fungus in the presence of

329 PCA, these trends continued with the colony again becoming taller and more dome shaped (Fig. S4B),

330 becoming anoxic at $280 \mu \mathrm{m}$ beneath its thicker layer of matrix. At no depth probed was oxygen again 331 detected.

Given the additional protection from PCA the $\Delta h r c A$ mutant provides, we speculated that it might contain a larger anoxic core even in the absence of PCA challenge/its fungal partner. When grown alone 
the surface and continued to a depth of $590 \mu \mathrm{m}(\mathbf{F i g} . \mathbf{5 A})$. In the presence of PCA, anoxia was reached at a depth of $250 \mu \mathrm{m}$ and continued to $660 \mu \mathrm{m}$, which resulted in similarly large anoxic interiors even as PCA caused an increase in matrix material at the surface of the colony (Fig. S4B). Intriguingly, the presence of the fungus and treatment with PCA resulted in the $\triangle h r c A$ mutant reaching anoxia at a similar depth as the PCA treatment alone at $230 \mu \mathrm{m}$, but the oxygen concentration declined more sharply. Oxygen again could not be detected at any depth when the fungus was present (Fig. 5A). significantly lowered the redox potential through their depth, maintaining a potential of greater than 280 $\mathrm{mV}$ in both cases, indicating an oxidizing environment. (Fig. 5B). This is not surprising because the absence of oxygen is necessary but not sufficient to create a reducing environment. When supplemented with PCA (the effective redox buffer), however, both strains showed a marked drop in redox potential to a low of approximately $-30 \mathrm{mV}$, although the $\Delta h r c A$ mutant maintained low redox potential over a greater depth and thus represents a larger volume of a reducing environment. When challenged with PCA in the produced by the bacterium, it is possible that the fungus helps maintain a reducing environment in partnership with $P$. edwinii.

\section{Fungal-induced pH shift corresponds with protection response}

While the Aspergillus species stimulated $P$. edwinii to generate anoxic and reducing interiors in

359 the presence of PCA, the fungus was not required to trigger these bacterial responses. However, the 
in the $\Delta h r c A$ strain (Fig. $\mathbf{4 E}$ ), suggesting the fungus may provide a stress-related trigger to the bacterium.

Many species of fungi will acidify their environment when stressed in an attempt to outcompete other microbes ${ }^{38}$. Accordingly, we hypothesized that our Aspergillus species might acidify the medium in response to PCA. In addition to the acid stress to which this would expose the bacterium, a lower $\mathrm{pH}$ results in a higher fraction of the PCA becoming protonated, and thus neutrally charged and more cell permeable, potentially forcing a response from $P$. edwinii. To test this hypothesis, we used a $\mathrm{pH}$ microelectrode to probe the $\mathrm{pH}$ of $P$. edwinii and Aspergillus colonies without PCA, with a slightly more acidic $\mathrm{pH}$ profile in the presence of PCA and an even more acidic profile in the presence of PCA + the fungus (Fig. 5C). Measurement of $\mathrm{pH}$ in fungal colonies alone showed that PCA exposure prompts the fungus to dramatically acidify its environment by $2-3 \log$ units

372 (Fig. 5C). Could acidification be a trigger for the protective response of $P$. edwinii? Given the dual stress

373 induced by acidification in the presence of PCA and the involvement of a stress regulator in the activation

374 of the protective PCA sequestration and reduction phenotype, we hypothesized that acidifying the medium could cause $P$. edwinii to behave as though its partner fungus is present even when absent. that previously required the fungal partner (Fig. 5D). We obtained similar results with citric acid, an organic acid made by some Aspergillus species and also commonly excreted from roots in the rhizosphere.

\section{Bacterial Protection of Fungi is not Specific to a Single Species Pairing}

To determine if mechanisms underpinning the protective partnership are general enough to allow other Paraburkholderia species to protect the Aspergillus isolate, we assayed the protective phenotype of three other Paraburkholderia species: $P$. SOS3, P. unamae, and P. phenazinium. P. SOS3 was isolated in

386 Australia and is genetically similar to P. edwinii; P. unamae was isolated from the corn roots in Mexico, 
making it a bonafide member of a food crop rhizosphere ${ }^{39}$; and $P$. phenazinium, though inhibitory to our fungal isolate when grown in tandem, is another known rhizosphere member and has the ability to form nitrogen fixing nodules ${ }^{40,41}$. When challenged with $300 \mu \mathrm{M}$ PCA, both $P$. SOS3 and P. unamae protected the Aspergillus isolate similar to $P$. edwinii, whereas $P$. phenazinium did not (Fig. 6A). If a pH shift helps prime the protective response, we similarly wondered whether $P$. edwinii may also protect other fungi, given that acidification is a general trait of filamentous fungi ${ }^{42,43}$. Accordingly, we tested the ability of $P$. edwinii to protect fungi from different niches, including a species of Fusarium isolated from infected corn seedling as well as clinical samples of the human opportunistic pathogens Aspergillus fumigatus and two Penicillium species isolated from the lungs of cystic fibrosis patients. While A. fumigatus is primarily thought of as a pathogen, many Penicillium species are thought to enhance plant growth while also being opportunistic humans pathogens. P. edwinii protected Aspergillus fumigatus, the Fusarium isolate, and one of the Penicillium isolates (Fig. 6B). edwinii between more distantly related fungi but selectivity between members of the same genus (e.g. Penicillium) suggests that while the mechanism of protection may be general, there are more factors involved that may help determine the success of such pairings in nature.

\section{Discussion}

This study was motivated by an ecological paradox: how do vulnerable fungi withstand the toxicity of a widespread class of antibiotics (phenazines) produced by co-occurring bacteria in the soil?

410 Given that soil microbial communities are diverse, we hypothesized that other bacteria in these niches

411 would confer protection through inter-domain partnerships. Our discovery of $P$. edwinii-the "prosperous friend" that helps its fungal partner withstand PCA challenge — establishes that such beneficial 
413 partnerships exist in nature and are likely common, a finding of basic interest that may also have

414 important practical implications.

415 While much remains to be learned about the mechanisms underpinning the P. edwinii-Aspergillus

416 partnership, our results underscore the importance of the biologically-controlled microenvironment and

417 the biochemical conversation that generates it. $P$. edwinii effectively serves as a "toxin sponge",

418 sequestering PCA in a reducing environment in response to acidification driven by an Aspergillus species.

419 The P. edwinni transcriptional repressor HrcA responds to the fungus, triggering the aggregation and PCA

420 sequestration pathways. Yet we do not know how PCA is sequestered by $P$. edwinii-whether it is

421 primarily stored extracellularly in the core of aggregates, or whether some fraction is held intracellularly.

422 Similarly, whether specific enzymes are required to generate and maintain the reducing environment is

423 unclear. A hint at an answer may be found in our mutagenic screen (Table S1): a transposon knockout of

424 the E1 subunit of the pyruvate dehydrogenase gene generated a mutant that actively harms the fungus in a

425 PCA dependent manner, with PCA crystals accumulating in the co-colony (Fig. 4A). Intriguingly,

427 Future experiments will reveal how the absence of this enzyme promotes PCA toxicity, and whether WT these and other mechanistic questions.

Our focus in this study on the $\triangle h r c A$ mutant derives from the fact that HcrA homologues are

432 stress-inducible transcriptional repressors. For example, heat appears to inactivate HrcA in B. subtilis,

433 releasing transcriptional repression of genes responsible for stress-tolerance ${ }^{30}$. An interesting possibility

434 is that HcrA in P. edwinii regulates some of the genes involved in reducing and sequestering PCA in

435 response to its fungal partner. If so, we speculate that HrcA degradation is not due to heat per se, but to

436 redox stress from PCA as well as acid or other stress produced by the fungus, where the latter stress could

437 increase the former. We also note that the $\Delta h r c A$ mutant appears to have its protection program partially

438 "activated" in the absence of these stressors, as the mutant will produce bacterial aggregates within the 
fungus even without PCA present and will sequester more PCA than WT despite being apart from its

fungal partner. That the $\Delta h r c A$ mutant can sequester still more PCA with the fungus present suggests

441 further regulators or triggers of the protection response await discovery.

environmentally relevant? We believe the answer is yes for several reasons. First, phenazine producers

444 are widespread in nature ${ }^{6}$ and thus odds are high that fungi will encounter them. Second, we were able to 445 readily isolate a variety of such partnerships. Third, PCA challenge leads to fungal acidification. $\mathrm{pH}$ is well known to play a critical role in determining phenazine toxicity as PCA becomes neutrally charged when protonated $(\mathrm{pKa}=4.24)$, leading it to more readily pass through cell membranes ${ }^{36,45}$. One study investigating the toxicity of PCA found that at a pH of 6.0, PCA showed virtually no toxicity to $C$. elegans, while at $\mathrm{pH} 5.0$ toxicity was very high ${ }^{36}$. Therefore, while fungal acidification can kill competing microbes, it can also render natural antibiotics made by certain bacteria more toxic. We thus predict that a fungus cooperating with an acid-tolerant beneficial bacterial partner would have a fitness advantage in phenazine-replete microbial communities. Fourth and finally, members of the these bacteria ideal partners to provide protection from phenazine assault to organisms which produce acid in response to stress. Intriguingly, many plant roots also produce organic acid exudates that may

457 reinforce such partnerships. Identifying which organic acids along with other stress signals protective

458 bacteria sense and respond to will be necessary for better understanding and predicting the environmental 459 relevance of these type of bacterial-fungal partnerships.

Given that PCA toxicity and production is predicted to increase in acidic soils that are vulnerable

461 to climate-induced drought due to enhanced oxygen penetration ${ }^{8,47}$, finding biological agents that can

462 protect fungi from phenazine toxicity may be relevant to agriculture. Many phenazine-sensitive

463 filamentous fungi in the rhizosphere play important roles in water and nutrient acquisition for their host 464 plants, and can help them withstand environmental stresses. Many Paraburkholderia species also have 
been implicated in plant health, and the $P$. unamae isolate which we found to confer resistance to phenazines in this study was originally isolated from the roots of corn ${ }^{39}$. Understanding how often

467 protective bacterial-fungal interactions occur in the rhizosphere may aid efforts to predict which microbial

468 community compositions impact crop yield, differential stress tolerance of crops, and susceptibility to

469 invasive pathogens. Additionally, though relatively little is known about phenazine interaction with the

470 more deeply penetrating arbuscular mycorrhizal fungi that help support tree survival, a recent study

471 suggests that phenazines could become toxic to this group of fungi if phenazine assault co-occurs with

472 other environmental stresses ${ }^{48}$. Finally, soil and plant-associated fungi are known to play a key role in

473 carbon sequestration, indicating that understanding how fungi can be included into phenazine replete

474 environments matters not just for plant growth on a warmer Earth, but also for maximizing our natural

475 reservoirs of sequestered carbon even as soil becomes less able to sequester carbon as global temperatures

476 rise ${ }^{3,49}$.

Importantly, it is also possible that fungal-bacterial partnerships are exploited by fungal

478 pathogens as well, as demonstrated by P. edwinii being capable of protecting a pathogenic Fusarium

479 isolate in this study. One study showed that when Paraburkholderia glathei was paired with the fungal

480 plant pathogens Alternaria alternata and Fusarium solani, P. glathei upregulated protein expression

481 associated with antibiotic tolerance and oxidative stress response, while downregulating its starvation

482 response ${ }^{50}$. These results raise the tantalizing possibility that this may be another example of a mutually

483 beneficial interspecies interaction competent to resist phenazine assault, where the bacterial stress

484 responses may serve to protect its partner fungus from other bacteria rather than defending itself from its

485 fungal host. Whether similar dynamics can play out in the context of the human host is also worth

486 exploring, given that pathogenic fungi such as Aspergillus fumigatus and Candida albicans can be co-

487 isolated from the lungs of cystic fibrosis patients with Pseudomonas aeruginosa ${ }^{51,52}$. Lung function is

488 negatively correlated with such coinfections, yet these fungi are largely inhibited by the phenazines

489 produced by $P$. aeruginosa ${ }^{32,53}$. Whether protective bacterial partners might help resolve this paradox

490 remains to be seen. 
Given the ease with which we isolated our model P. edwinii-Aspergillus pairing and the relative

492 promiscuity of the protective bacterial partner and/or fungus being protected, we posit that interspecies

493 cooperation may be an important method by which fungal membership in microbial communities is

494 determined. This insight has important implications for diverse problems concerning environmental and

495 human health. We hope that the model system established in this study will enable basic biological

496 insights to be gained that will facilitate such partnerships to be exploited for human benefit in the future.

\section{Materials and Methods}

\section{Strains and Media}

502 Strains used in this study are listed in Table S2. E coli S17 was used for cloning and conjugation of the

503 pMQ30 suicide vector during construction of deletion mutants. E. coli strain B2155 was used for mating 504 of the mini-mariner containing pSC189. All E. coli were grown overnight in $5 \mathrm{~mL}$ lysogeny broth (LB), 505 supplemented with $300 \mu \mathrm{M}$ diaminopimelic acid (DAP) for B2155. Strains were grown shaking at 250 $506 \quad \mathrm{RPM}$ at $37^{\circ} \mathrm{C}$ for cloning constructs and $30^{\circ} \mathrm{C}$ when used for conjugations. Pseudomonas fluorescens 2507 79, Pseudomonas chlororaphis, Pseudomonas chlororaphis subsp. aureofaciens were grown overnight in $5085 \mathrm{ml} \mathrm{LB}$ at $30{ }^{\circ} \mathrm{C}$ shaking at $250 \mathrm{rpm}$. Paraburkholderia phenazinium, Paraburkholderia unamae, 509 Paraburkholderia SOS3, and Paraburkholderia edwinii were grown 24 hours under the same conditions 510 in $5 \mathrm{~mL}$ potato dextrose broth (PDB) unless otherwise indicated.

511 The environmental Aspergillus isolate was grown on potato dextrose agar (PDA) at $30^{\circ} \mathrm{C}$, and all

512 experiments which paired $P$. edwinii and the Aspergillus isolate were grown for 48 hours unless otherwise

513 indicated. Clinical Aspergillus fumigatus as well as Penicillium species isolates were obtained from

514 Children's' Hospital Los Angeles, and were grown under the same conditions. Growth on PDA for 1

515 week at $30{ }^{\circ} \mathrm{C}$ to allow conidiation was performed on all fungi to collect spores for storage and 
experimentation. Fungal conidiospores were collected by scraping mature colonies with a pipette tip,

517 filtering the spores through cheesecloth, and freezing in 15\% glycerol. All PDA plates contained 1.75\%

518 agar, while all other plates contained $1.5 \%$ agar.

519 Co-isolation of phenazine tolerant fungal-bacterial pairings.

$520100 \mathrm{mg}$ of material was collected within the top 3 centimeters of top soil from outside of the Beckman

521 Institute on the campus of the California Institute of Technology $\left(34^{\circ} 8{ }^{\prime} 21.15^{\prime \prime} \mathrm{N} 118^{\circ} 7^{\prime} 36.05^{\prime \prime} \mathrm{W}\right)$. The

522 collected soil was washed in $0.1 \%$ TWEEN® 20 and pulsed in a sonicator bath for one minute to break up

523 larger soil components. A serial dilution of the suspension was plated to extinction on potato dextrose

524 medium. Fungal colonies were screened for adherent bacterial associates via amplification of the $16 \mathrm{~S}$

525 rRNA encoding region of the bacterial genomes, and discovered pairings were subjected to challenge on

526 potato dextrose agar supplemented with $300 \mu \mathrm{M}$ phenazine-1-carboxylic acid. Surviving co-colonies were

527 serially passaged in yeast-peptone (YP) medium to isolate the bacterium. The fungal partners were cured

528 by growth on YP medium supplemented with $50 \mu \mathrm{g} \mathrm{ml}^{-1}$ gentamicin, repatched onto PDA and grown for

529 one week at $30{ }^{\circ} \mathrm{C}$ until conidiation. Spores were collected and frozen in $12.5 \%$ glycerol.

Phenazine Protection Assay

$531 P$. edwinii was grown shaking overnight in potato dextrose broth at $30^{\circ} \mathrm{C}$. Cultures were normalized to

532 OD600 of 2.5, diluted 1:5, and mixed 1:1 with a suspension of $\sim 4 \times 10^{7}$ spores collected from the

533 Aspergillus species. 6 ul of this mixture was spotted onto potato dextrose plates supplemented with 300

$534 \mu \mathrm{M}$ PCA and allowed to grow for 48 hours before measuring the co-colony diameter with the aid of

535 Keyence digital microscope (VHX-600).

Mutant transposon screen of $P$. edwinii.

537 Transposon mutagenesis of $P$. edwinii was achieved using a mini-mariner transposon housed in the

538 pSC189 vector and mutants were generated as follows. P. edwinii was grown overnight in potato dextrose

539 broth, and the pSC189 vector-containing B2155 strain of E. coli was grown in LB with $50 \mu \mathrm{g} \mathrm{ml}^{-1}$ 

media before being resuspended in $100 \mu \mathrm{l}$ of YP. The strains were mixed together and several $5 \mu 1$

543 replicates were plated on YP plates overnight. Colonies were then scraped up and grown on YP plates

544 lacking DAP and containing $30 \mu \mathrm{g} \mathrm{ml}^{-1}$ kanamycin to select for transposon insertions. Colonies were

545 picked after two days and grown overnight in a 96 well plate in YP containing $60 \mu \mathrm{g} \mathrm{ml}^{-1}$ kanamycin.

546 Mutants were mixed with spores of the Aspergillus species and grown on potato dextrose supplemented

547 with PCA as above to screen for a dysregulated protection response. Mutants of interest had their transposition insertion mapped using arbitrary PCR.

\section{Construction of in-frame deletion and complementation strains in P. edwinii.}

In-frame deletions were constructed in $P$. edwinii using homologous recombination as previously described in Pseudomonas species with modification ${ }^{54} . \sim 1 \mathrm{~KB}$ regions upstream and downstream of the

552 genomic region to be deleted were cloned into the pMQ30 suicide vector at the SmaI site, and the

553 resulting constructs were electroporated into the S17 E. coli strain. Matings were conducted as described

554 above, and the resulting mated colonies were scraped up and plated on potato dextrose containing $50 \mu \mathrm{g}$

$555 \mathrm{ml}^{-1}$ gentamycin and $15 \mu \mathrm{g} \mathrm{ml}^{-1}$ chloramphenicol. Colonies were restreaked on selective plates, and

556 finally patched onto YP plates amended with 7.5\% (w/v) sucrose. Candidate colonies grown after $48 \mathrm{~h}$

557 were screened by polymerase chain reaction to identify those containing the desired in-frame deletions.

558 The pBBR1MCS-2 expression plasmid was used for complementation experiments. The gene of interest

559 plus a 24 bp region upstream of the start codon were cloned into the plasmid and electroporated into $P$.

560 edwinii using the following protocol. P. edwinii was grown overnight in potato dextrose broth. 4-5 mL of

561 the culture was spun down and washed twice with $20 \%(\mathrm{w} / \mathrm{v})$ sucrose at room temperature, before

562 resuspending it in $100 \mu \mathrm{l}$ of $20 \%$ (w/v) sucrose. $100 \mathrm{ng}$ of the plasmid was added to $50 \mu \mathrm{L}$ of the

563 resuspended culture and electroporated using standard E. coli settings. Cells were allowed to recover for 2

$564 \mathrm{~h}$ in $\mathrm{YP}$ at $30{ }^{\circ} \mathrm{C}$ before plating to YP plates containing $30 \mu \mathrm{g} \mathrm{ml}^{-1}$ kanamycin. Colonies were grown 
shaking overnight in potato dextrose broth with $60 \mu \mathrm{g} \mathrm{ml}^{-1}$ kanamycin before being used in growth assays without antibiotic selection as described above.

\section{Biofilm assay}

568 V8 medium was produced by diluting V8 tomato juice 1:5 with $\mathrm{ddH}_{2} \mathrm{O}$ the same day of the experiment.

569 Overnight $P$. edwinii cultures grown in potato dextrose broth were normalized to an OD600 of 2.5 and

570 diluted 1:67 in the V8 medium and vortexed. $100 \mathrm{uL}$ was pipetted per well into 96 well microtiter dishes

571 as described for other systems ${ }^{31}$. Biofilms were stored in a humidified microchamber and allowed to

572 grow for 24 hours at $30{ }^{\circ} \mathrm{C}$ before being stained with $0.1 \%$ crystal violet for 20 minutes, and rinsed twice

573 with $\mathrm{ddH}_{2} \mathrm{O}$.

\section{Motility assay}

575 P. edwinii strains were tested for motility using a swim assay. A modified M9 medium lacking added

$576 \mathrm{NaCl}$ was made using $0.35 \%$ agar. Strains of $P$. edwinii were normalized to an OD600 of 2.5 and $100 \mu \mathrm{L}$

577 was pipetted into a 96 well microtiter dish. A p10 pipette tip was dipped into one of these wells and

578 subsequently plunged into the swim agar. Plates were incubated at $30{ }^{\circ} \mathrm{C}$ for $72 \mathrm{~h}$.

\section{$579 \quad$ Phenazine sequestration assay}

$5805 \mu \mathrm{l}$ each of a spore suspension from the Aspergillus species and an overnight culture of $P$. edwinii normalized to OD600 2.5 were spotted $5 \mathrm{ul}$ apart from each other on potato dextrose agar supplemented with $300 \mathrm{uM}$ PCA and grown until the P. edwinii colonies developed a distinct yellow hue, approximately 48 h. Material from the P. edwinii colonies was then collected and resuspended in $250 \mathrm{uL}$ Phosphate

584 buffer saline solution (PBS). The samples were centrifuged and the supernatant was read for absorbance at $365 \mathrm{~nm}$ in a spectrophotometer and compared to a standard curve to derive PCA concentration. The

586 pelleted fraction of the sample was dried and weighed to normalize sequestered PCA to bacterial dry

587 weight mass. 
This procedure was repeated to determine the fraction of reduced PCA present, but samples were collected and analyzed in an anerobic chamber, and the reduced PCA was identified using an excitation of

$590 \quad 365 \mathrm{~nm}$ and read at an emission of $528 \mathrm{~nm}$ on a BioTek plate reader. Concentration was calculated using a

591 standard curve of reduced PCA and compared to the total PCA concentration to determine the reduced

592 fraction.

\section{PCA Degradation Assay}

594 P. edwinii was added to $5 \mathrm{ml}$ of PDB that was spiked with $300 \mu \mathrm{M}$ PCA. For combined bacterial-fungal 595 samples, the Aspergillus isolate was pre-grown in the medium for 3 days to allow an appreciable amount 596 of slower growing fungal biomass to coexist with the subsequently added $P$. edwinii and PCA. $250 \mu 1$ was 597 sampled every 24 hours for 3 days, and all cultures had reached stationary phase by the first sampling.

598 Cells were pelleted, and the supernatant was used to quantify PCA by absorbance at $365 \mathrm{~nm}$ compared to 599 a standard curve and PCA negative control.

600 Microelectrode Profiling

601 Aspergillus and P. edwinii colonies were grown side by side or alone on PDA as above for $48 \mathrm{~h}$ at $30{ }^{\circ} \mathrm{C}$.

602 Unisense $\mathrm{pH}$ and redox $25 \mu \mathrm{m}$ tip microelectrodes were paired with a steel reference probe (Unisense) in

603 accordance with the manufacturer's instructions for use and calibration, and were readthrough a high-

604 impedance millivoltmeter-equipped multimeter, while a $10 \mu \mathrm{m}$ tip $\mathrm{O}_{2}$ probe was read through the

605 multimeter's picoampere amplifier. Oxygen concentration was read at $10 \mu \mathrm{m}$ interval depths within the

606 colonies, while $\mathrm{pH}$ and redox values were read at $25 \mu \mathrm{m}$ intervals through the colonies. Redox values are

607 given relative to a standard hydrogen electrode. Initial calibration and recording of data were performed

608 using the Unisense SensorTrace Suite software. All calibrations and measurements were conducted at 23

$609{ }^{\circ} \mathrm{C}$. 
611 Fungal tissue was cleared using the MiPACT procedure as described previously with minor modification

$612{ }^{28}$. Briefly, samples were grown for $48 \mathrm{~h}$, and whole co-colonies cut from their growth medium, removing

613 as much agar as possible. Samples were incubated at $4{ }^{\circ} \mathrm{C}$ overnight in $3 \%(\mathrm{v} / \mathrm{v})$ paraformaldehyde.

614 Samples were cleared for 2 weeks in a spinning $8 \%$ (w/v) SDS solution at $37^{\circ} \mathrm{C}$. Samples were washed in

615 PBS, treated with $1 \mathrm{mg} \mathrm{ml}^{-1}$ lysozyme for 30 minutes at $30^{\circ} \mathrm{C}$ before being hybridized with HCR 2.0

616 eubacterial probes and incubated overnight at $46{ }^{\circ} \mathrm{C}$ while gently shaking. Samples were washed and the

617 amplification step was performed using hairpins tagged with an alexa 647 fluorophore for visualization.

618 Samples were stained with $1 \mu \mathrm{g} \mathrm{ml}^{-1} \mathrm{DAPI}$, and microscopy was performed on an inverted confocal Leica

619 model TCS SPE confocal microscope with a 10x objective for the colony center and edge, and a Nikon

620 Ti2 Eclipse widefield microscope with a 4x objective for images of the colony ridge. Contrast of the HCR

621 generated images were normalized to the brightest signal in like samples (i.e. colony edge vs edge, center

622 vs center). Contrast was adjusted independently for each DAPI stained images for clarity of fungal

623 morphology present near the bacteria.

\section{CFU Quantification}

625 Fungal-bacterial co-colonies were grown as above, and the colonies were homogenized using a tissue

626 homogenizer (Bio-Gen Pro200) at 60\% power for one minute. The resulting slurry was serially diluted

627 and plated to YP medium supplemented with $50 \mu \mathrm{g} \mathrm{ml}^{-1}$ nystatin to prevent fungal growth. Bacterial

628 colonies were grown for $48 \mathrm{~h}$ and counted.

$630 P$. edwinii colonies were scraped from their growth plates and resuspended in phosphate buffer saline

631 before being pelleted. Supernatants were frozen and thawed to encourage precipitation of large particulate

632 condiments, and centrifuged using a cellulose acetate Spin-X column (VWR). $20 \mathrm{ul}$ of the supernatant

633 was injected onto a Waters e2695 Separations Module equipped with a 2998 PDA Detector and run

634 through a C18 column (XBridge, $3.5 \mathrm{um}, 2.1 \times 50 \mathrm{~mm}$ ) housed at $40{ }^{\circ} \mathrm{C}$ at a flow rate of $0.5 \mathrm{ml} \mathrm{min}^{-1}$ for 


\section{Acknowledgements}

20 mins. The mobile phase consisted of $\mathrm{ddH} 20+0.04 \%$ (v/v) $\mathrm{NH}_{4} \mathrm{OH}$ with a gradient to $70 \%$ (v/v) acetonitrile $+0.04 \%(\mathrm{v} / \mathrm{v}) \mathrm{NH}_{4} \mathrm{OH}$ with a constant background of $2 \%(\mathrm{v} / \mathrm{v})$ methanol and compared against a prepared standard. The identify of PCA was confirmed using a quadrupole Time of Flight MS (Q-TOF, Xevo G2-XS, Waters) targeting a mass of $224.2 \mathrm{~m} / \mathrm{z}$.

\section{Genomic Sequencing and Annotation}

P. edwinii genomic DNA was recovered using the Qiagen plant and tissue kit on $1 \mathrm{~mL}$ of culture grown overnight in PDB. Genomic DNA from the Aspergillus species was recovered by growing it for $72 \mathrm{~h}$ in PDB until large fungal aggregates had formed. These aggregates were frozen in liquid nitrogen, and crushed with a mortar and pestle followed by a chloroform extraction.

Illumina sequencing of both genomes was conducted at the Caltech genomic core facility, and subsequent PACBio sequencing was carried out at the UC Irvine Genomics High Throughput Facility. Genome assembly was performed using SPAdes version 3.12.0, and BASys was used for genome annotation of $P$. edwinii as provided by the Health Sciences Library System at the University of Pittsburg.

We thank members of the Newman lab for constructive feedback on the project and the manuscript, and The Millard and Muriel Jacobs Genetics and Genomics Laboratory at Caltech and Igor Antoshechkin for support during library preparation and sequencing. We thank Marko Kojic for help screening transposon mutants, as well as Robert Cramer, Deborah Hogan, and Jeff Holloman for sharing their expertise in mycology. This work was supported by the Life Sciences Research Foundation (postdoctoral fellowship to K.M.D.), the Resnick Institute (K.M.D. and D.K.N.) and the NIH (1R01AI127850- 01A1 to D.K.N.). 


\section{References}

1. Delfino, E., Del Puente, F., Briano, F., Sepulcri, C., and Giacobbe, D.R. (2019). Respiratory Fungal Diseases in Adult Patients With Cystic Fibrosis. Clin Med Insights Circ Respir Pulm Med 13.

2. Jahagirdar, S., Kambrekar, D.N., Navi, S.S., and Kunta, M. (2019). Plant Growth-Promoting Fungi: Diversity and Classification. In Bioactive Molecules in Plant Defense: Signaling in Growth and Stress, S. Jogaiah and M. Abdelrahman, eds. (Springer International Publishing), pp. 25-34.

3. Soudzilovskaia, N.A., van Bodegom, P.M., Terrer, C., Zelfde, M. van't, McCallum, I., Luke McCormack, M., Fisher, J.B., Brundrett, M.C., de Sá, N.C., and Tedersoo, L. (2019). Global mycorrhizal plant distribution linked to terrestrial carbon stocks. Nature Communications 10, 5077.

4. Chin, T., Bloemberg, G., Bij, A., Drift, K., Schripsema, J., Kroon, B., Scheffer, R., Keel, C., Bakker, P., Tichy, H.-V., et al. (1998). Biocontrol by Phenazine-1-carboxamide-Producing Pseudomonas chlororaphis PCL1391 of Tomato Root Rot Caused by Fusarium oxysporum f. sp. radicis-lycopersici. Mol Plant Microbe Interact 11, 1069-1077.

5. Thomashow, L.S., and Weller, D.M. (1988). Role of a phenazine antibiotic from Pseudomonas fluorescens in biological control of Gaeumannomyces graminis var. tritici. J Bacteriol 170, 34993508.

6. Dar, D., Thomashow, L.S., Weller, D.M., and Newman, D.K. (2020). Global landscape of phenazine biosynthesis and biodegradation reveals species-specific colonization patterns in agricultural soils and crop microbiomes. eLife 9, e59726.

7. Mavrodi, O.V., Mavrodi, D.V., Parejko, J.A., Thomashow, L.S., and Weller, D.M. (2012). Irrigation Differentially Impacts Populations of Indigenous Antibiotic-Producing Pseudomonas spp. in the Rhizosphere of Wheat. Appl. Environ. Microbiol. 78, 3214-3220.

8. Mavrodi, D.V., Mavrodi, O.V., Elbourne, L.D.H., Tetu, S., Bonsall, R.F., Parejko, J., Yang, M., Paulsen, I.T., Weller, D.M., and Thomashow, L.S. (2018). Long-Term Irrigation Affects the Dynamics and Activity of the Wheat Rhizosphere Microbiome. Front Plant Sci 9.

9. Trejo-Hernández, A., Andrade-Domínguez, A., Hernández, M., and Encarnación, S. (2014). Interspecies competition triggers virulence and mutability in Candida albicans - Pseudomonas aeruginosa mixed biofilms. The ISME Journal 8, 1974-1988.

10. Sass, G., Ansari, S.R., Dietl, A.-M., Déziel, E., Haas, H., and Stevens, D.A. (2019). Intermicrobial interaction: Aspergillus fumigatus siderophores protect against competition by Pseudomonas aeruginosa. PLOS ONE 14, e0216085.

11. Pan, S.K., and Das, A. (2010). In Vivo Interaction in Antagonistic Potential of Trichoderma spp. and Pseudomonas fluorescens. Journal of Biological Control 24, 263-267.

12. Patel, N.P., Raju, M., Haldar, S., and Chatterjee, P.B. (2020). Characterization of phenazine-1carboxylic acid by Klebsiella sp. NP-C49 from the coral environment in Gulf of Kutch, India. Arch Microbiol 202, 351-359. 
13. Amin, R., Dupuis, A., Aaron, S.D., and Ratjen, F. (2010). The effect of chronic infection with Aspergillus fumigatus on lung function and hospitalization in patients with cystic fibrosis. Chest 137, 171-176.

14. Bonfante, P., and Genre, A. (2010). Mechanisms underlying beneficial plant-fungus interactions in mycorrhizal symbiosis. Nature Communications 1, 48.

15. Marjanović, Ž., and Nehls, U. (2008). Ectomycorrhiza and Water Transport. In Mycorrhiza: State of the Art, Genetics and Molecular Biology, Eco-Function, Biotechnology, Eco-Physiology, Structure and Systematics, A. Varma, ed. (Springer), pp. 149-159.

16. Varsha, K.K., Nishant, G., Sneha, S.M., Shilpa, G., Devendra, L., Priya, S., and Nampoothiri, K.M. (2016). Antifungal, Anticancer and Aminopeptidase Inhibitory Potential of a Phenazine Compound Produced by Lactococcus BSN307. Indian J Microbiol 56, 411-416.

17. Fisher, M.C., Henk, D.A., Briggs, C.J., Brownstein, J.S., Madoff, L.C., McCraw, S.L., and Gurr, S.J. (2012). Emerging fungal threats to animal, plant and ecosystem health. Nature 484, 186-194.

18. Perry, E.K., and Newman, D.K. (2019). The transcription factors ActR and SoxR differentially affect the phenazine tolerance of Agrobacterium tumefaciens. Molecular Microbiology 112, 199-218.

19. Costa, K.C., Bergkessel, M., Saunders, S., Korlach, J., and Newman, D.K. (2015). Enzymatic Degradation of Phenazines Can Generate Energy and Protect Sensitive Organisms from Toxicity. mBio 6.

20. Yang, Z.-J., Wang, W., Jin, Y., Hu, H.-B., Zhang, X.-H., and Xu, Y.-Q. (2007). Isolation, Identification, and Degradation Characteristics of Phenazine-1-Carboxylic Acid-Degrading Strain Sphingomonas sp. DP58. Curr Microbiol 55, 284-287.

21. Nazir, R., Tazetdinova, D.I., and Elsas, J.D. van (2014). Burkholderia terrae BS001 migrates proficiently with diverse fungal hosts through soil and provides protection from antifungal agents. Frontiers in Microbiology 5, undefined-undefined.

22. Partida-Martinez, L.P., and Hertweck, C. (2005). Pathogenic fungus harbours endosymbiotic bacteria for toxin production. Nature 437, 884-888.

23. Seigle-Murandi, F., Guiraud, P., Croize, J., Falsen, E., and Eriksson, K.L. (1996). Bacteria Are Omnipresent on Phanerochaete chrysosporium Burdsall. Applied and environmental microbiology $62,2477-2481$.

24. Bahram, M., Hildebrand, F., Forslund, S.K., Anderson, J.L., Soudzilovskaia, N.A., Bodegom, P.M., Bengtsson-Palme, J., Anslan, S., Coelho, L.P., Harend, H., et al. (2018). Structure and function of the global topsoil microbiome. Nature 560, 233-237.

25. Levy, A., Merritt, A.J., Mayo, M.J., Chang, B.J., Abbott, L.K., and Inglis, T.J.J. (2009). Association between Burkholderia species and arbuscular mycorrhizal fungus spores in soil. Soil Biology and Biochemistry 41, 1757-1759. 
26. Simionato, A.S., Navarro, M.O.P., de Jesus, M.L.A., Barazetti, A.R., da Silva, C.S., Simões, G.C., BalbiPeña, M.I., de Mello, J.C.P., Panagio, L.A., de Almeida, R.S.C., et al. (2017). The Effect of Phenazine1-Carboxylic Acid on Mycelial Growth of Botrytis cinerea Produced by Pseudomonas aeruginosa LV Strain. Front Microbiol 8.

27. Mavrodi, D.V., Ksenzenko, V.N., Bonsall, R.F., Cook, R.J., Boronin, A.M., and Thomashow, L.S. (1998). A Seven-Gene Locus for Synthesis of Phenazine-1-Carboxylic Acid by Pseudomonas fluorescens 2-79. J Bacteriol 180, 2541-2548.

28. DePas, W.H., Starwalt-Lee, R., Sambeek, L.V., Kumar, S.R., Gradinaru, V., and Newman, D.K. (2016). Exposing the Three-Dimensional Biogeography and Metabolic States of Pathogens in Cystic Fibrosis Sputum via Hydrogel Embedding, Clearing, and rRNA Labeling. mBio 7.

29. Chiang, S.L., and Rubin, E.J. (2002). Construction of a mariner-based transposon for epitope-tagging and genomic targeting. Gene 296, 179-185.

30. Schulz, A., and Schumann, W. (1996). hrcA, the first gene of the Bacillus subtilis dnaK operon encodes a negative regulator of class I heat shock genes. J Bacteriol 178, 1088-1093.

31. O'Toole, G.A., and Kolter, R. (1998). Initiation of biofilm formation in Pseudomonas fluorescens WCS365 proceeds via multiple, convergent signalling pathways: a genetic analysis. Molecular Microbiology 28, 449-461.

32. Morales, D.K., Grahl, N., Okegbe, C., Dietrich, L.E.P., Jacobs, N.J., and Hogan, D.A. (2013). Control of Candida albicans Metabolism and Biofilm Formation by Pseudomonas aeruginosa Phenazines. mBio 4, e00526-12.

33. Rada, B., and Leto, T.L. (2013). Pyocyanin effects on respiratory epithelium: relevance in Pseudomonas aeruginosa airway infections. Trends Microbiol 21, 73-81.

34. Allen, L., Dockrell, D.H., Pattery, T., Lee, D.G., Cornelis, P., Hellewell, P.G., and Whyte, M.K.B. (2005). Pyocyanin production by Pseudomonas aeruginosa induces neutrophil apoptosis and impairs neutrophil-mediated host defenses in vivo. J Immunol 174, 3643-3649.

35. Zhu, X., Zeng, Y., Zhao, X., Zou, S., He, Y.-W., and Liang, Y. (2017). A genetic screen in combination with biochemical analysis in Saccharomyces cerevisiae indicates that phenazine-1-carboxylic acid is harmful to vesicular trafficking and autophagy. Scientific Reports 7, 1967.

36. Cezairliyan, B., Vinayavekhin, N., Grenfell-Lee, D., Yuen, G., Saghatelian, A., and Ausubel, F. (2013). Identification of Pseudomonas aeruginosa Phenazines that Kill Caenorhabditis elegans. PLoS pathogens 9, e1003101.

37. Zhang, L., Tian, X., Kuang, S., Liu, G., Zhang, C., and Sun, C. (2017). Antagonistic Activity and Mode of Action of Phenazine-1-Carboxylic Acid, Produced by Marine Bacterium Pseudomonas aeruginosa PA31x, Against Vibrio anguillarum In vitro and in a Zebrafish In vivo Model. Front Microbiol 8.

38. Liaud, N., Giniés, C., Navarro, D., Fabre, N., Crapart, S., Gimbert, I.H.-, Levasseur, A., Raouche, S., and Sigoillot, J.-C. (2014). Exploring fungal biodiversity: organic acid production by 66 strains of filamentous fungi. Fungal Biology and Biotechnology 1, 1. 
39. Caballero-Mellado, J., Martínez-Aguilar, L., Paredes-Valdez, G., and Estrada-de los Santos, P. (2004). Burkholderia unamae sp. nov., an N2-fixing rhizospheric and endophytic species. International journal of systematic and evolutionary microbiology $54,1165-72$.

40. Dias, G.M., Pires, A. de S., Grilo, V.S., Castro, M.R., Vilela, L. de F., and Neves, B.C. (2019). Comparative genomics of Paraburkholderia kururiensis and its potential in bioremediation, biofertilization, and biocontrol of plant pathogens. MicrobiologyOpen 8, e00801.

41. Viallard, V., Poirier, I., Cournoyer, B., Haurat, J., Wiebkin, S., Ophel-Keller, K., and Balandreau, J. (1998). Burkholderia graminis sp. nov., a rhizospheric Burkholderia species, and reassessment of [Pseudomonas] phenazinium, [Pseudomonas] pyrrocinia and [Pseudomonas] glathei as Burkholderia. International Journal of Systematic and Evolutionary Microbiology, 48, 549-563.

42. Tkacz, J.S., and Lange, L. eds. (2004). Advances in Fungal Biotechnology for Industry, Agriculture, and Medicine (Springer US).

43. Andersen, M.R., Lehmann, L., and Nielsen, J. (2009). Systemic analysis of the response of Aspergillus niger to ambient $\mathrm{pH}$. Genome Biol 10, R47.

44. Glasser, N.R., Wang, B.X., Hoy, J.A., and Newman, D.K. (2017). The Pyruvate and $\alpha$-Ketoglutarate Dehydrogenase Complexes of Pseudomonas aeruginosa Catalyze Pyocyanin and Phenazine-1carboxylic Acid Reduction via the Subunit Dihydrolipoamide Dehydrogenase *. Journal of Biological Chemistry 292, 5593-5607.

45. Brisbane, P.G., Janik, L.J., Tate, M.E., and Warren, R.F. (1987). Revised structure for the phenazine antibiotic from Pseudomonas fluorescens 2-79 (NRRL B-15132). Antimicrob Agents Chemother 31, 1967-1971.

46. Stopnisek, N., Bodenhausen, N., Frey, B., Fierer, N., Eberl, L., and Weisskopf, L. (2014). Genus-wide acid tolerance accounts for the biogeographical distribution of soil Burkholderia populations. Environ Microbiol 16, 1503-1512.

47. Mavrodi, D.V., Mavrodi, O.V., Parejko, J.A., Bonsall, R.F., Kwak, Y.-S., Paulitz, T.C., Thomashow, L.S., and Weller, D.M. (2012). Accumulation of the Antibiotic Phenazine-1-Carboxylic Acid in the Rhizosphere of Dryland Cereals. Appl. Environ. Microbiol. 78, 804-812.

48. Dwivedi, D., Johri, B.N., Ineichen, K., Wray, V., and Wiemken, A. (2009). Impact of antifungals producing rhizobacteria on the performance of Vigna radiata in the presence of arbuscular mycorrhizal fungi. Mycorrhiza 19, 559-570.

49. Varney, R.M., Chadburn, S.E., Friedlingstein, P., Burke, E.J., Koven, C.D., Hugelius, G., and Cox, P.M. (2020). A spatial emergent constraint on the sensitivity of soil carbon turnover to global warming. Nature Communications 11, 5544.

50. Stopnisek, N., Zühlke, D., Carlier, A., Barberán, A., Fierer, N., Becher, D., Riedel, K., Eberl, L., and Weisskopf, L. (2016). Molecular mechanisms underlying the close association between soil Burkholderia and fungi. ISME J 10, 253-264. 
51. Al-momani, H., Perry, A., Stewart, C.J., Jones, R., Krishnan, A., Robertson, A.G., Bourke, S., Doe, S., Cummings, S.P., Anderson, A., et al. (2016). Microbiological profiles of sputum and gastric juice aspirates in Cystic Fibrosis patients. Scientific Reports 6, 26985.

52. Peleg, A., Hogan, D., and Mylonakis, E. (2010). Medically important bacterial-fungal interactions. Nature reviews. Microbiology 8, 340-9.

53. Briard, B., Bomme, P., Lechner, B.E., Mislin, G.L.A., Lair, V., Prévost, M.-C., Latgé, J.-P., Haas, H., and Beauvais, A. (2015). Pseudomonas aeruginosa manipulates redox and iron homeostasis of its microbiota partner Aspergillus fumigatus via phenazines. Sci Rep 5, 8220.

54. Shanks, R.M.Q., Caiazza, N.C., Hinsa, S.M., Toutain, C.M., and O'Toole, G.A. (2006). Saccharomyces cerevisiae-Based Molecular Tool Kit for Manipulation of Genes from Gram-Negative Bacteria. Appl Environ Microbiol 72, 5027-5036. 
Fig. 1. Co-isolation of a fungus and protective bacterial partner. A) $100 \mathrm{mg}$ of top soil samples were washed in PBS with $0.01 \%$ Tween 20, sonicated to break apart soil and loosely associated microbes, and plated on PDA. Colonies were screened for bacterial partners by $16 \mathrm{~S}$ amplification, and pairings were subsequently cured of their partners and tested by PCA challenge. B) An Aspergillus isolate from the soil growing on PDA (column, top). The same isolate fails to grow in the presence of $300 \mu \mathrm{M}$ PCA after 48 hours (column, center), but is capable of withstanding phenazine assault when grown with its co-isolated partner, $P$. edwinii (column, bottom). When $P$. edwinii is grown alone next to $P$. fluorescens, it can be engulfed by the phenazine-producing strain (bottom row, left) but not the phenazine mutant strain, ::phzD (bottom row, right). C) The isolated Aspergillus species is inhibited by a wide array of phenazine producing organisms (left column), The bacterial competitors and primary phenazines they produce, top to bottom, are Pseudomonas chlororaphis (phenazine-1-carboxamide), Pseudomonas aureofaciens (2hydroxyphenazine), Pseudomonas fluorescens (PCA), and Paraburkholderia phenazinium (iodinin). Fungal growth is enhanced in the same conditions by the presence of $P$. edwinii (right column). Also note $P$. fluorescens is incapable of engulfing the co-colony as it did to P. edwinii alone in B. Bacterial aggregates are visible in several images. All colonies were grown on PDA for $48 \mathrm{hrs}$ at $30^{\circ} \mathrm{C}$.

Fig. 2. P. edwinii forms aggregates in center of fungal colony in response to PCA challenge. Bacteria gather along the edge of the mycelia (left column) and mixed throughout the interior of the fungal colony (right center column). When challenged with PCA, P. edwinii forms congregates less at the leading edge of the mycelium (left center column) but aggregates within the colony center (right column). Whole colonies were grown on PDA for 48 hours at $30^{\circ} \mathrm{C}$, processed using the MiPACT technique to render fungal tissue transparent, and visualized using HCR eubacterial probes and DAPI (see materials and methods). Eubacterial probes were labeled with a with an Alexa 647 fluorophore. Images are representative of three independently grown co-colonies for each condition, and were captured on an inverted confocal Leica model TCS SPE confocal microscope with a 10x objective. Images of the HCR signal were normalized in contrast to the brightest image in like samples (i.e. edge vs edge, or center vs center), while images of the DAPI signal were independently adjusted to best outline fungal morphology in the vicinity of the bacteria.

Fig. 3. P. edwinii acts as a toxin sponge. A) The Aspergillus species and P. edwinii growing on PDA supplemented with $300 \mu \mathrm{M}$ PCA growing at a distance (top) and $5 \mathrm{~mm}$ apart (bottom). Note the Aspergillus growth toward the bacterium and deepening yellow color of $P$. edwinii when the two organisms are grown in proximity of one another. Images are representative of 5 sets of colonies. B) HPLC chromatogram with the peak representing PCA derived from scraped up P. edwinii colonies grown with or without its fungal partner, and in the presence of absence of PCA challenge. C) nmoles PCA sequestered by $P$. edwinii in the absence and presence of its partner fungus, normalized by bacterial dry mass. Quantification was performed by measuring absorbance at $365 \mathrm{~nm}$. Error bars represent standard deviation of four biological replicates. *** $\mathrm{p}<0.001$. D) Fraction of reduced PCA present (left) in a $P$. edwinii or Pseudomonas fluorescens colony when grown as a three-member system with the isolated Aspergillus species (right). Reduced PCA was quantified by fluorescence spectroscopy using an excitation wavelength of $365 \mathrm{~nm}$ and reading emission at $520 \mathrm{~nm}$. Error bars represent standard deviation of 3 biological replicates.

858 Fig. 4. $\mathbf{~ r c A}$ regulates the protection response of P. edwinii. A) Transposon mutants of $P$. edwinii that 
PCA, organized from less bacterial aggregation/protection to most. B) An in-frame deletion of the $h r c A$ gene was constructed to verify the transposon phenotype, and was complemented using the pBBR1 expression vector. C) $\Delta h r c A$ shows a greater degree of fungal protection compared to the WT strain. Error bars represent standard deviation of four biological replicates. $* * * p<0.001$. D) Comparison of WT and $\triangle h r c A$ CFUs derived from co-colonies. Whole co-colonies exposed or not exposed to PCA challenge were excised from PDA plates, homogenized, and plated on PDA supplemented with nystatin to prevent fungal growth. Reported is the total number of CFUs per co-colony. Error bars represent standard deviation of four biological replicates. ${ }^{*} \mathrm{p}<0.05, * * \mathrm{p}<0.01$. E) Comparison of the ability of WT and $\triangle h r c A$ to sequester PCA with and without partner fungus. Error bars represent standard deviation of four biological replicates. $* \mathrm{p}<0.05$. F) Biofilm and motility assay of WT and $\triangle h r c A$. The WT strain shows increased biofilm formation and motility (top images) compared to $\Delta h r c A$ (bottom images). The biofilm formation assay utilized $1 / 5 \mathrm{~V} 8$ medium and was grown for 24 hours at $30^{\circ} \mathrm{C}$ before staining with $0.1 \%$ crystal violet, while the motility assay was conducted in modified M9 medium for 72 hours at $30^{\circ} \mathrm{C}$. Error bars represent standard deviation of four biological replicates. $* * * p<0.001$.

\section{Fig. 5. P. edwinii and Aspergillus species respond to PCA challenge by modifying oxygen} availability, reduction potential, and $\mathbf{p H}$. A) Oxygen profile of $P$. edwinii colonies. The WT colony grows as a flat disc in the absence of PCA, but becomes rounded with an apparent outer polysaccharide layer when stressed with PCA, and the increase in colony volume creates a larger anoxic zone beneath this layer than exists in the non-stress condition (left). $\triangle h r c A$ shows a similar trend but more closely resembles the WT PCA (+) condition even when not challenged (right). B) When challenged with PCA, WT and $\triangle h r c A$ P. edwinii colonies generate more reducing conditions. The larger zone of lower reducing potential in the $\triangle h r c A$ mutant compared to WT when exposed to PCA is reflective of the larger internal volume this mutant creates. The addition of the Aspergillus isolate causes a further decrease in reduction potential that is sustained to greater depths (left right)C) The WT and $\Delta h r c A P$. edwinii colonies generate near-neutral $\mathrm{pH}$ conditions that show a trend of decreasing when exposed to PCA, and growing the fungus adjacent to $P$. edwinii colonies causes the internal environment to be more acidic (Left, Center). The Aspergillus isolate generates alkaline conditions when grown without PCA challenge, but generates a much more acidic environment when PCA is present (Right. Error bars for all microelectrode experiments represent standard deviation of three measurements at each depth. D) Addition of $5 \mathrm{mM} \mathrm{HCl}$ or citric acid causes an increase in PCA sequestration in P. edwinii colonies. Colonies were grown for $48 \mathrm{hrs}$ at $30^{\circ} \mathrm{C}$. All adjacent colonies were grown $5 \mathrm{~mm}$ apart. Error bars represent standard deviation of four biological replicates. $* * p<0.01$

\section{Fig. 6. The protection response is conserved in other Paraburkholderia species and shows partial} specificity. A) The ability to protect the Aspergillus isolate was tested among several species of Paraburkholderia. Left to right: No bacterium added, $P$. unamae, $P$. SOS3, and $P$. phenazinium. The protection response was present in $P$. unamae and $P$. SOS3, isolated from the roots of corn in Mexico and from top soil in Australia, respectively. P. phenazinium, itself a phenazine producer capable of producing iodinin, appeared to demonstrate no fungal growth. B) $P$. edwinii tested for gross ability to protect plant and human pathogenic fungi. From left to right: a phytopathogenic Fusarium species isolated in our lab, three opportunistic human pathogenic fungi isolated from the lungs of CF patients including Aspergillus fumigatus and two Penicillium species. White bars demonstrate the diameter of each fungus in PCA treated condition for comparison with the mixed co-colonies. All samples were grown for $48 \mathrm{hrs}$ at $30^{\circ} \mathrm{C}$. 
bioRxiv preprint doi: https://doi.org/10.1101/2021.03.28.437412; this version posted March 28, 2021. The copyright holder for this preprint (which was not certified by peer review) is the author/funder, who has granted bioRxiv a license to display the preprint in perpetuity. It is made available under aCC-BY-NC-ND 4.0 International license.

905 


\section{Figure 1}

\section{A. Soil Sample}

\section{Weakly Associated}

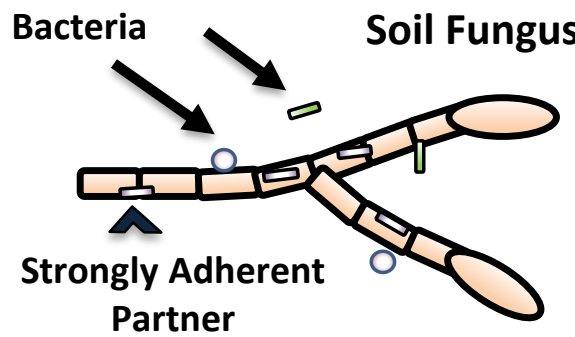
Partner

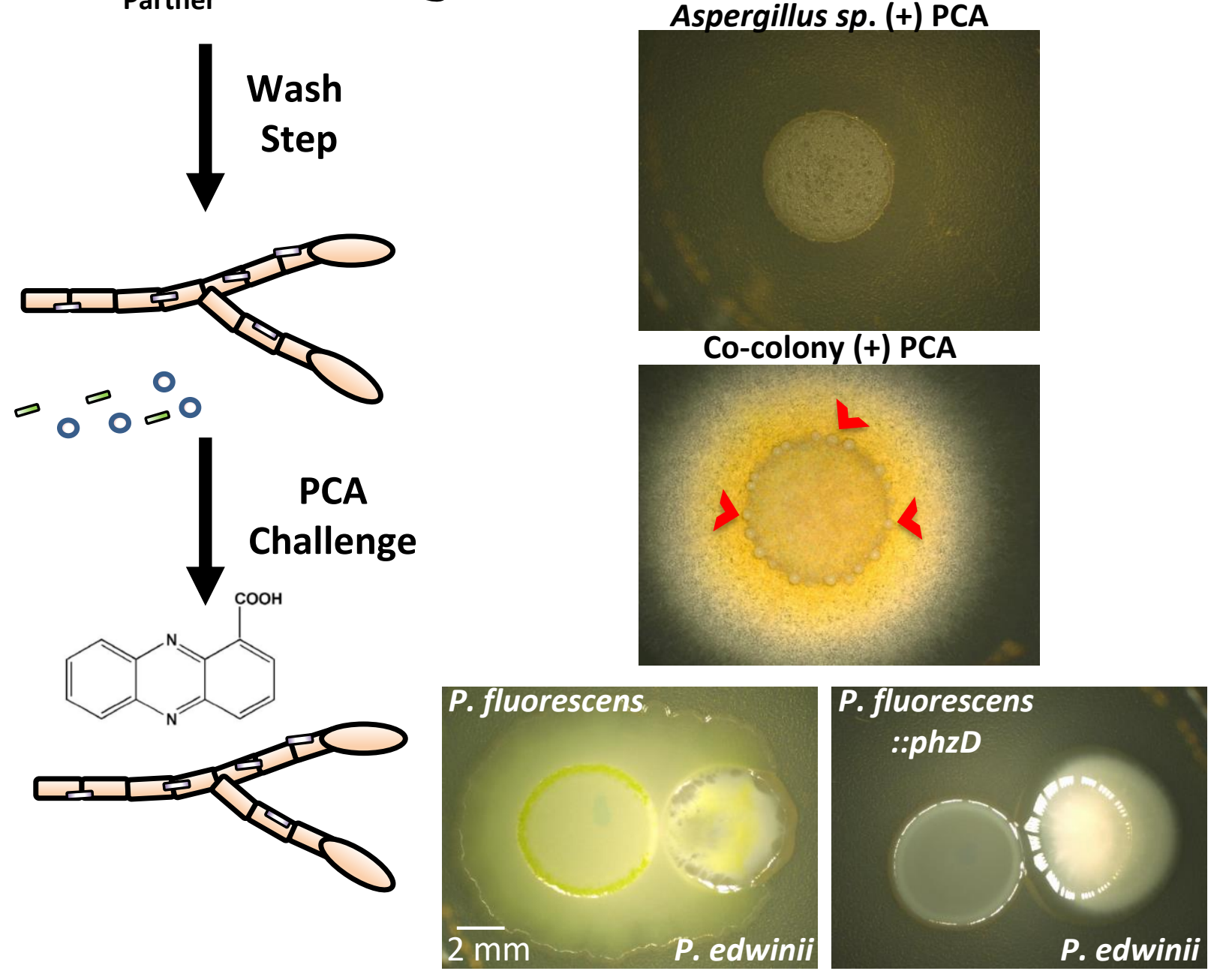

B. Aspergillus sp. (-) PCA
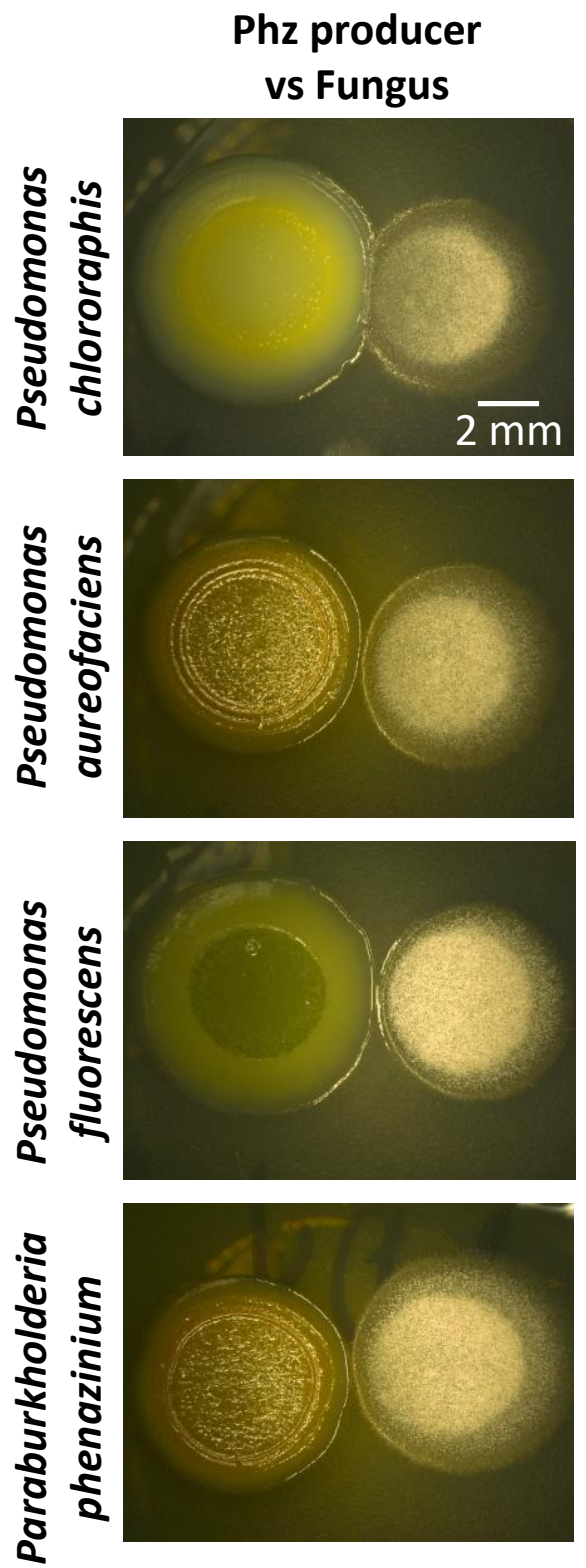

Phz producer vs Co-colony
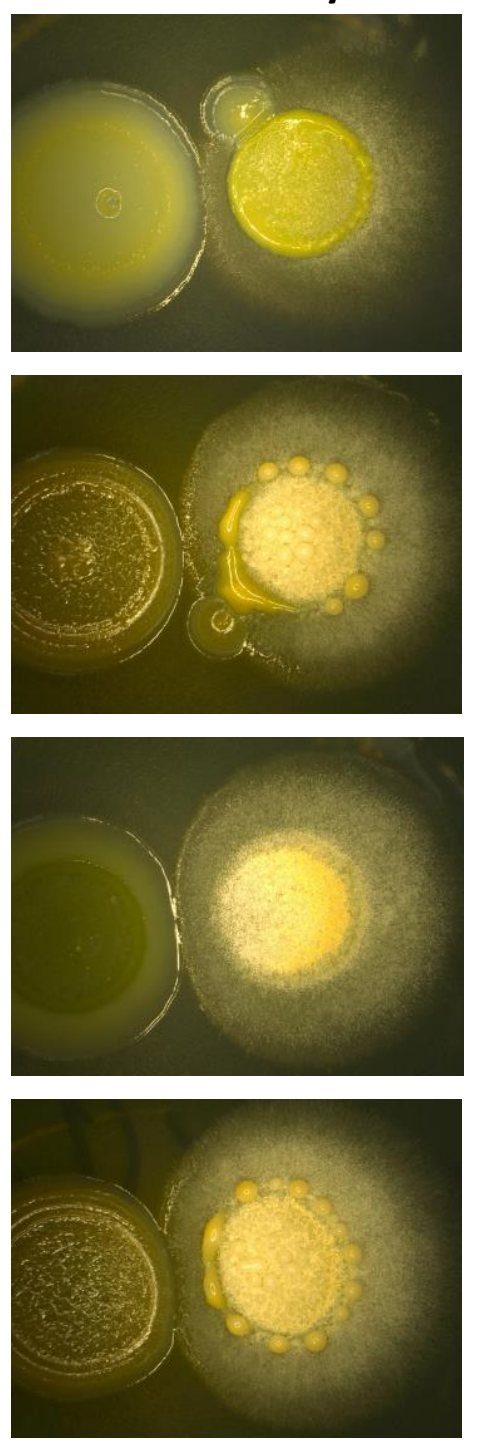
Colony Edge (-) PCA

$\overline{100 \mu m}$

Eubacteria HCR

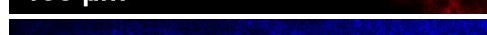

$\overline{100 \mu \mathrm{m}}$

Colony Edge (+) PCA

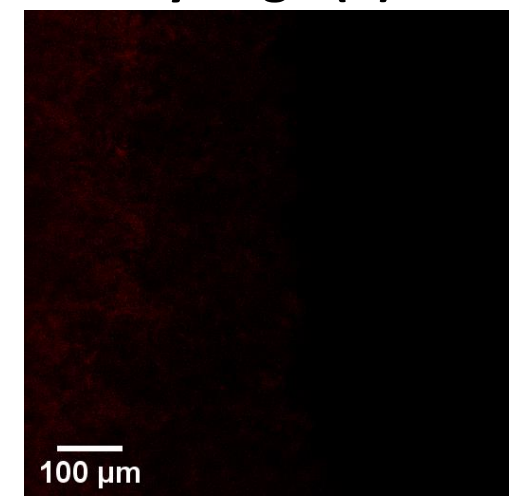

$100 \mu \mathrm{m}$

Colony Center (-) PCA
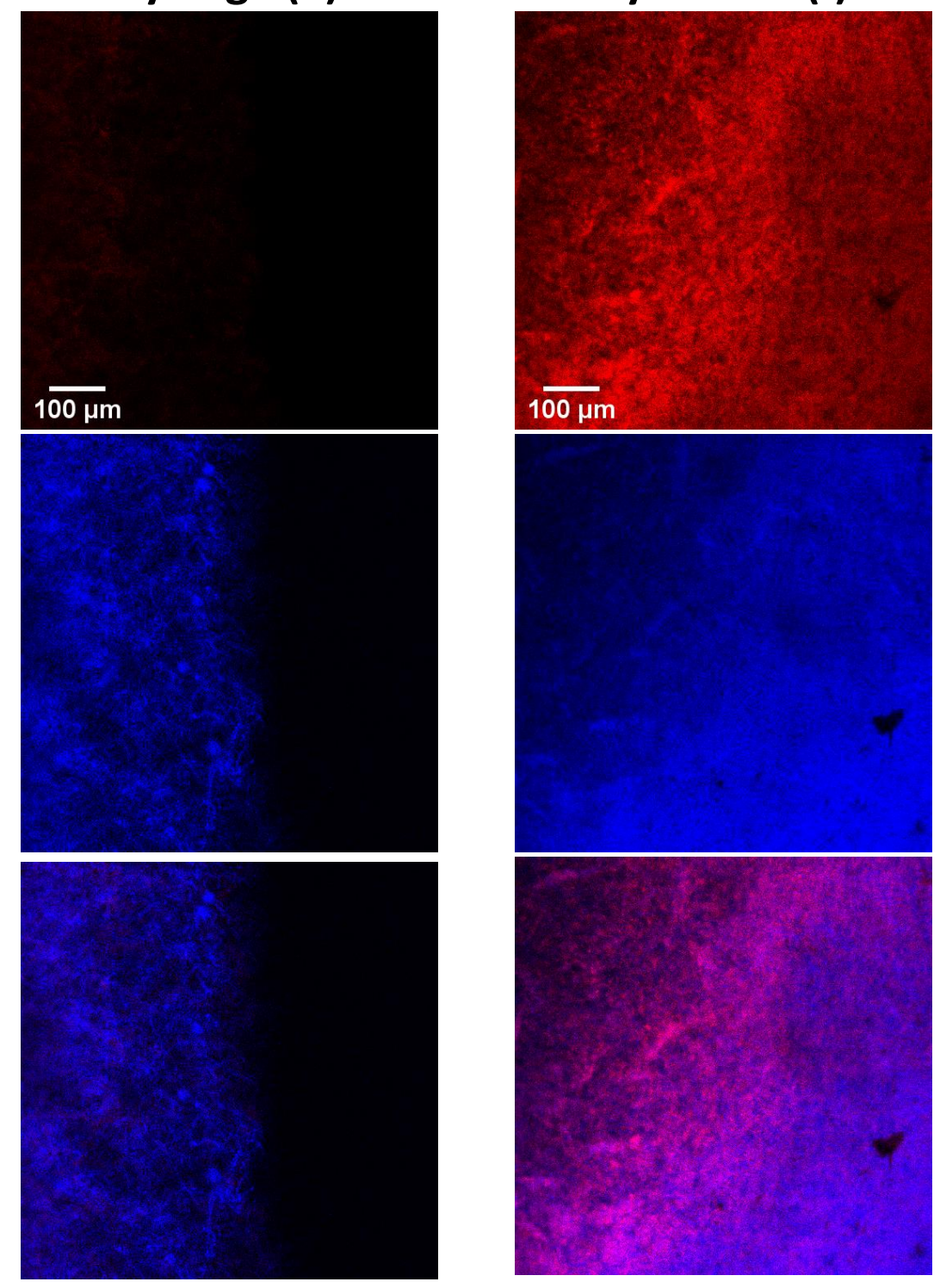

Colony Center (+) PCA

$\overline{100 \mu \mathrm{m}}$

Merge

DAPI
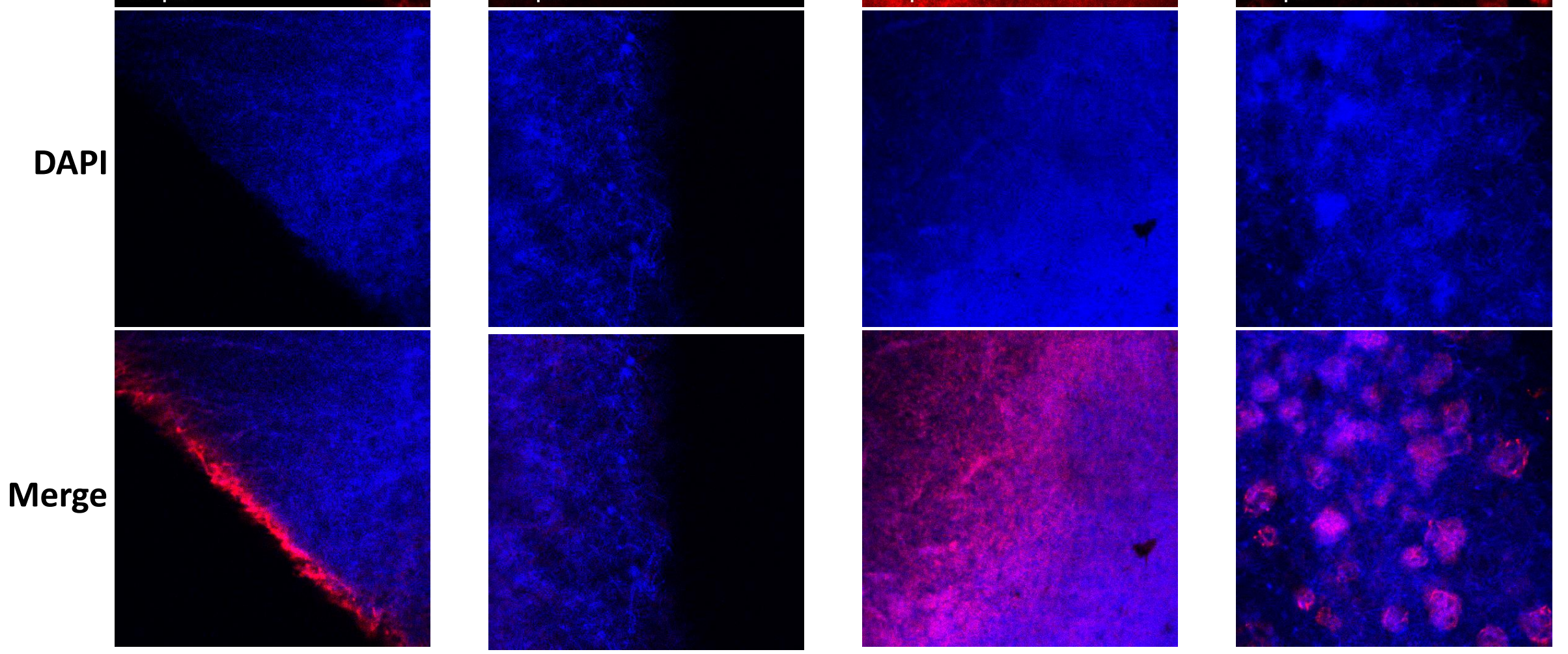
(-) PCA

A

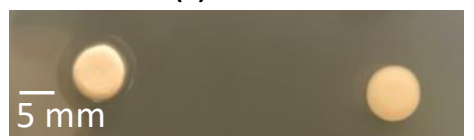

Aspergillus sp. P. edwinii

(+) PCA

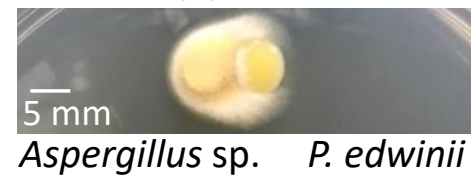

C

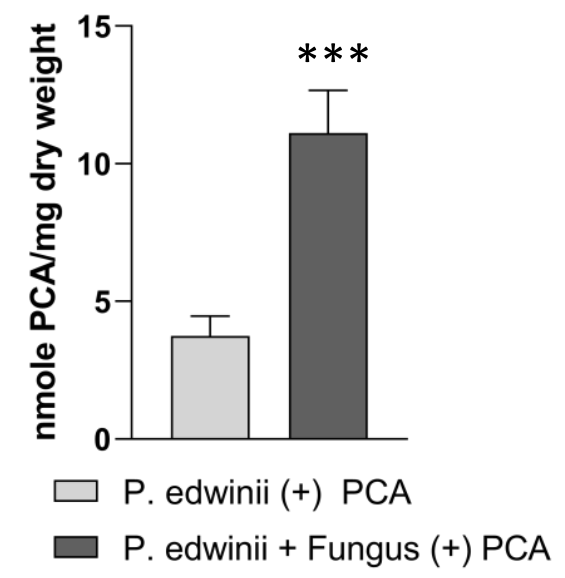

B

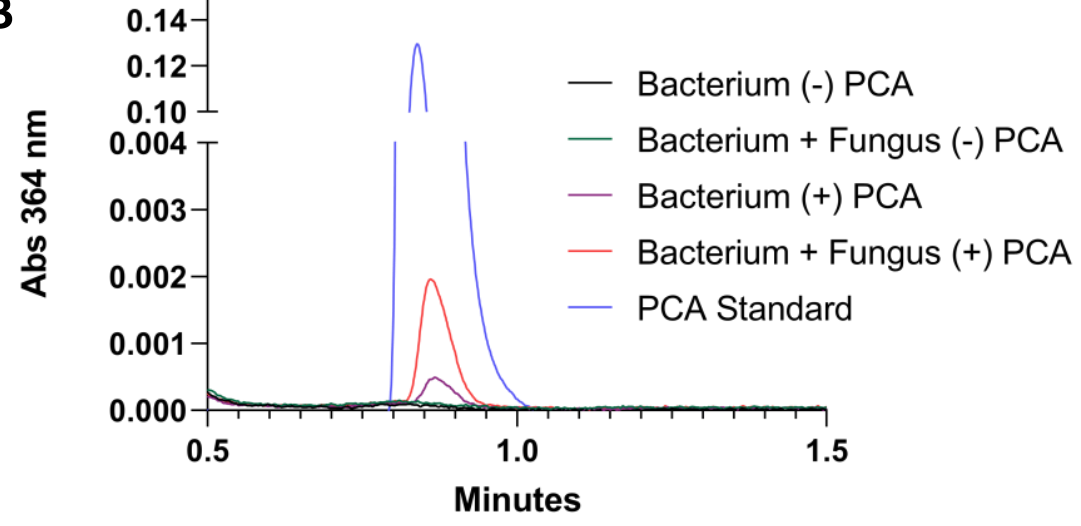

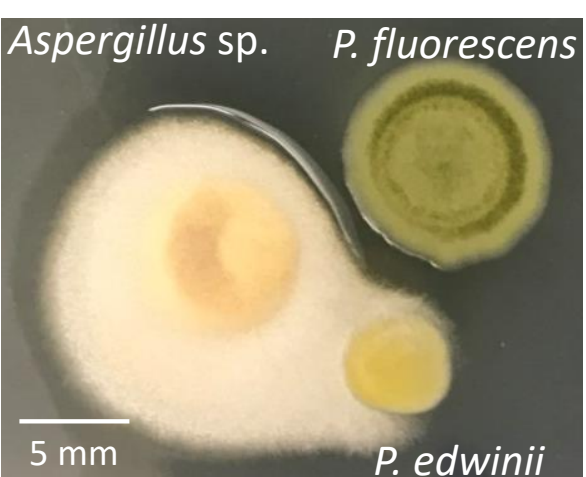

D

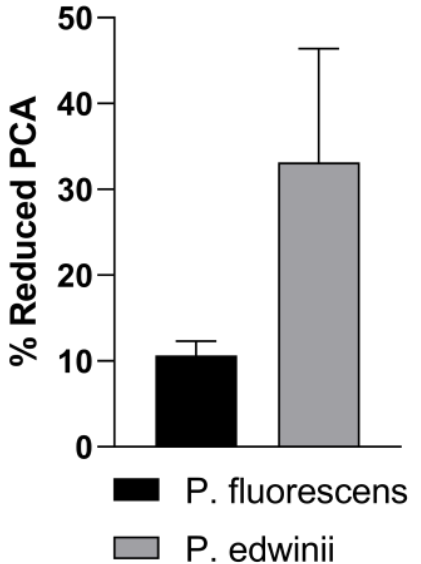


Figure 4

Pyruvate

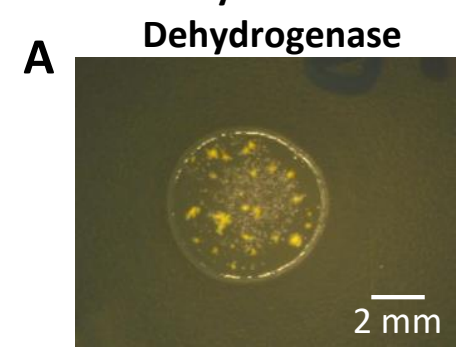

Transcriptional

Repressor hrcA

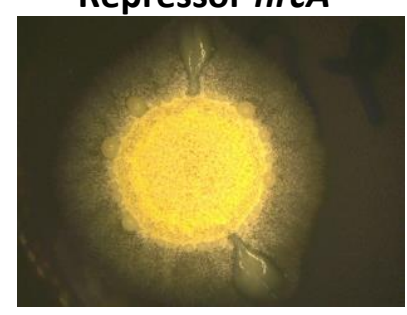

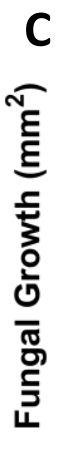

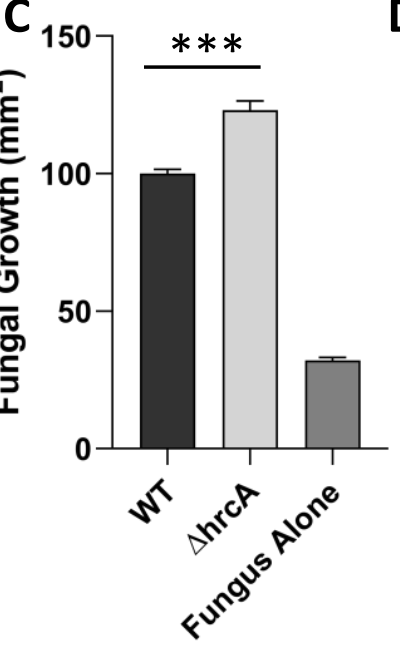

Potassium Transporter

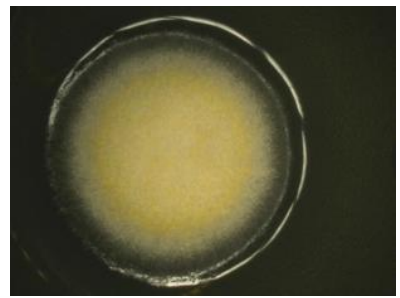

flgE
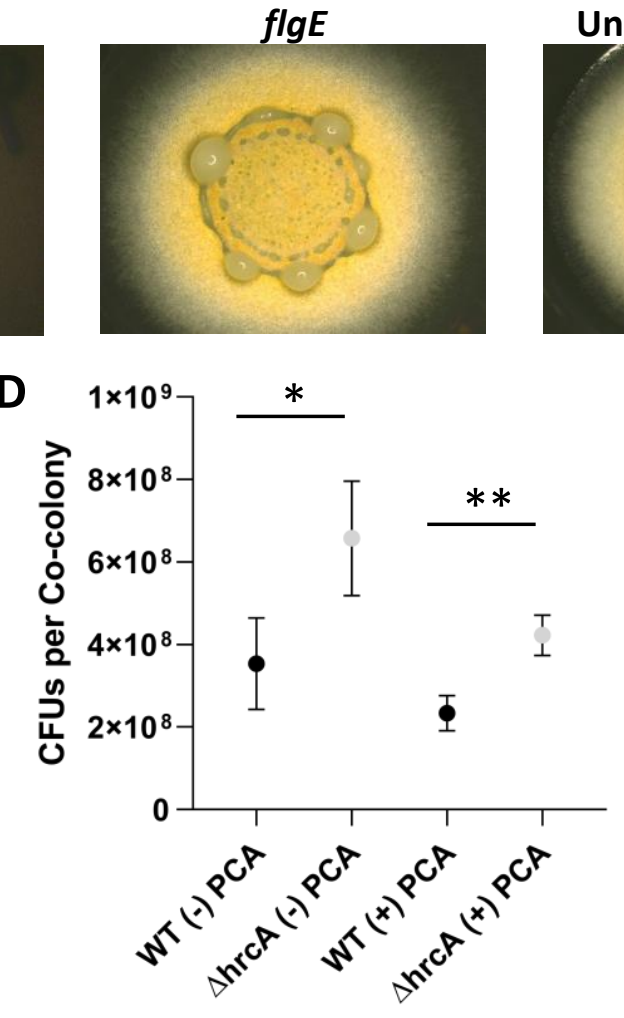

LysR Transcription Factor

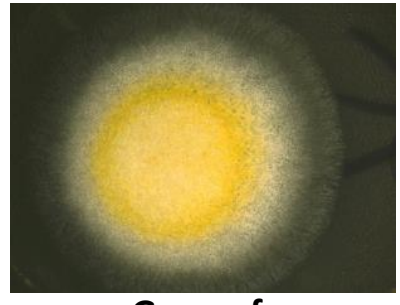

Gene of

Unknown Function
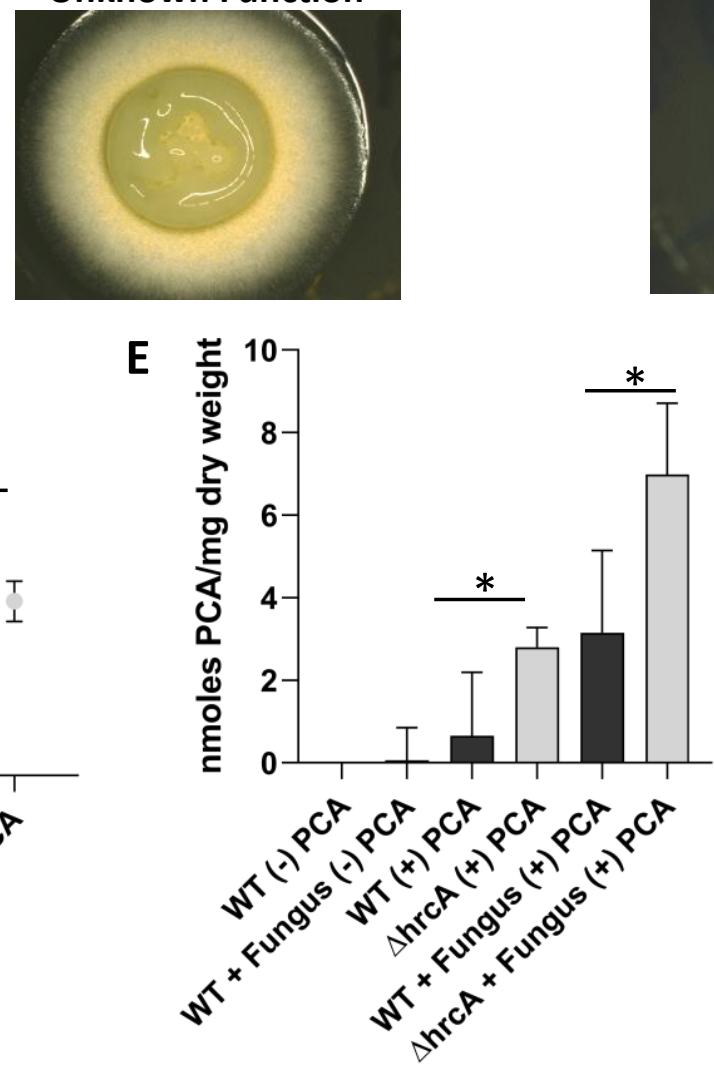

WT

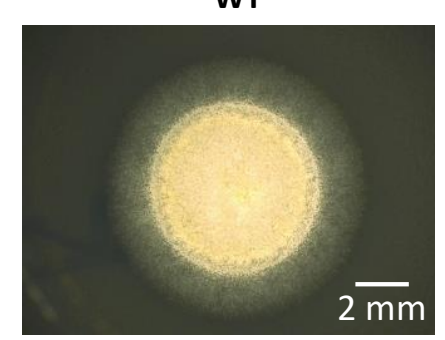

$\Delta h r c A+p B B R 1$ hrcA

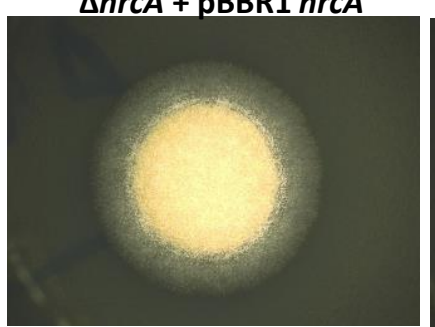

F
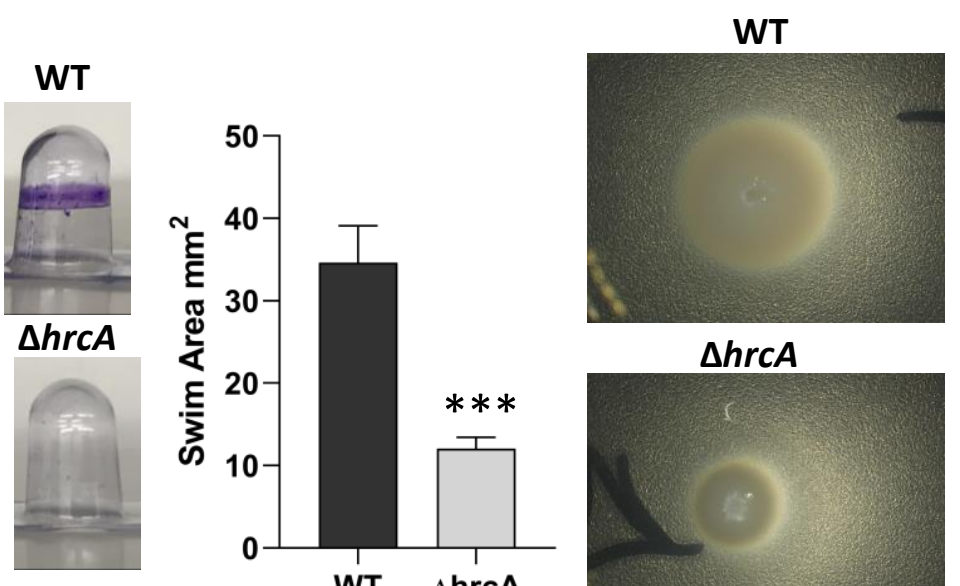

$\Delta h r c A$
$\Delta h r c A+p B B R 1$ backbone
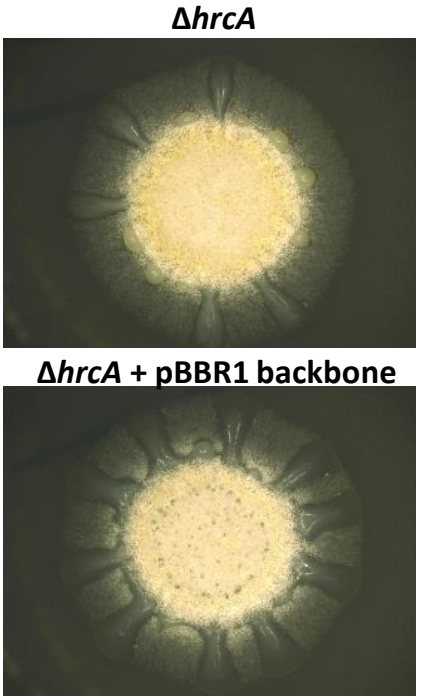

这

है 20

क 10

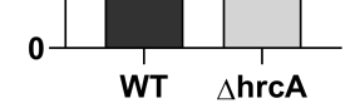

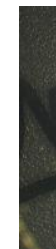

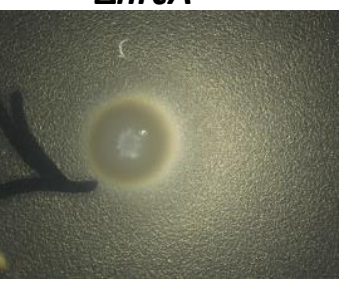




\section{Figure 5}
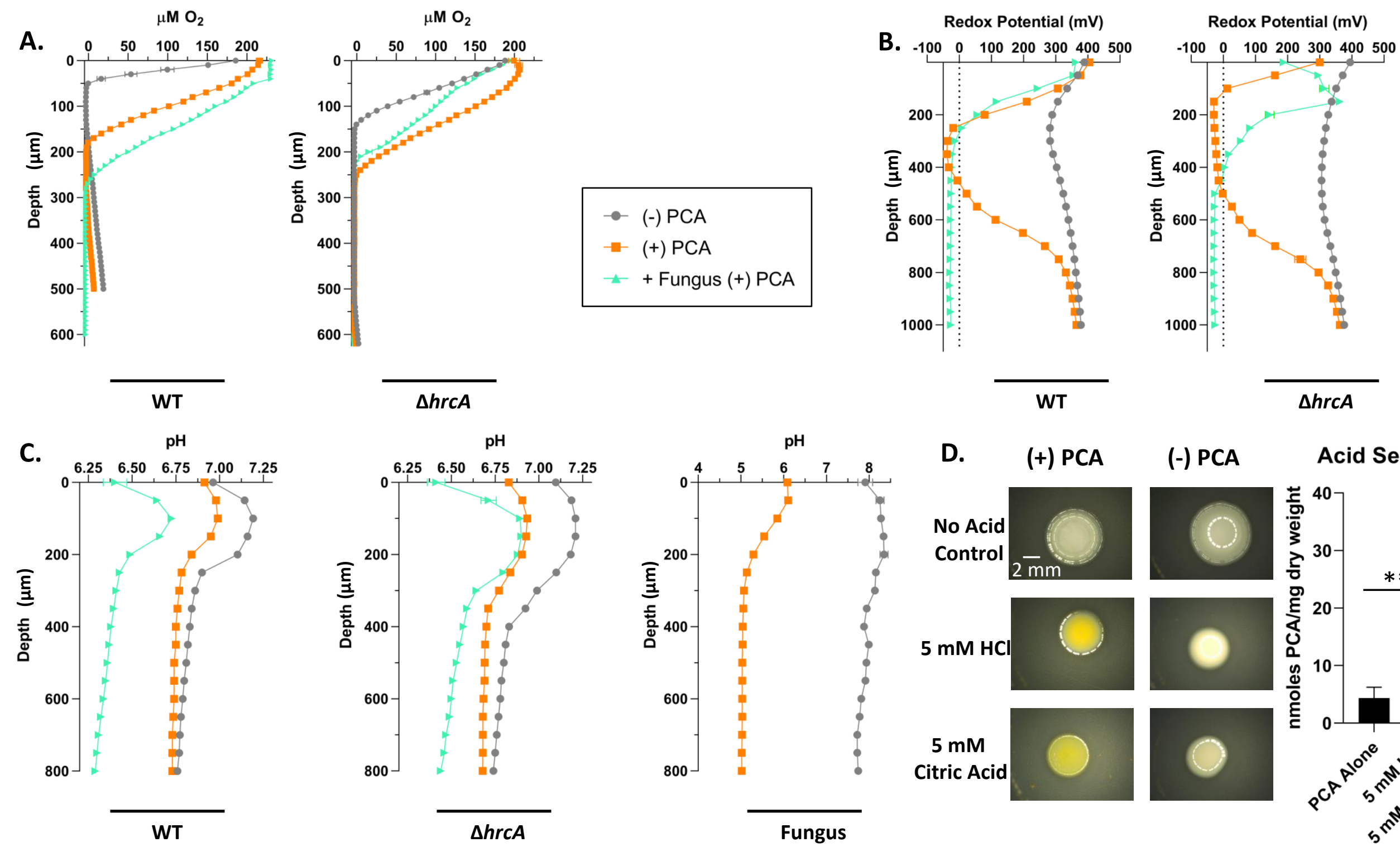

D. (+) PCA

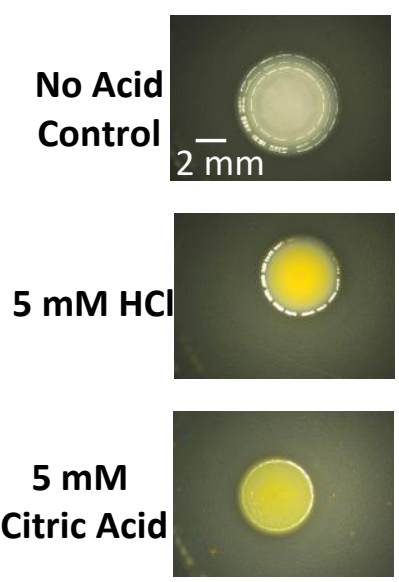

(-) PCA

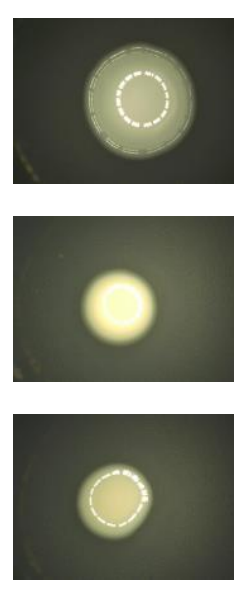

Acid Sequestration

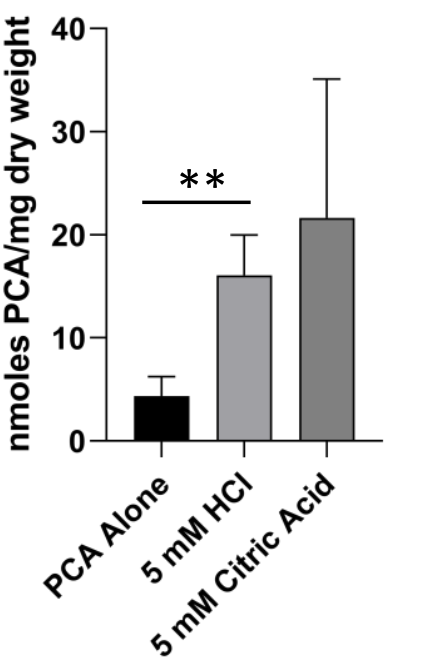


(+) P. SOS3

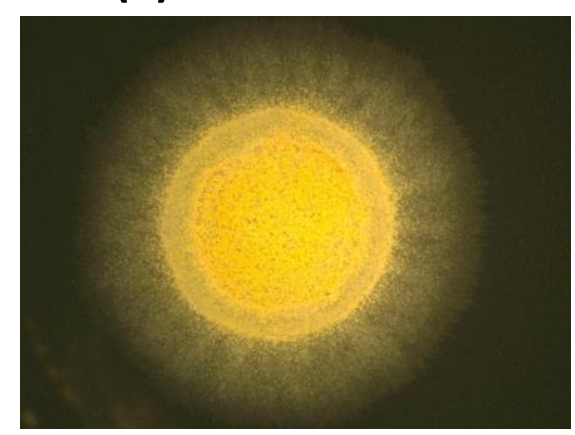

Penicillium sp.
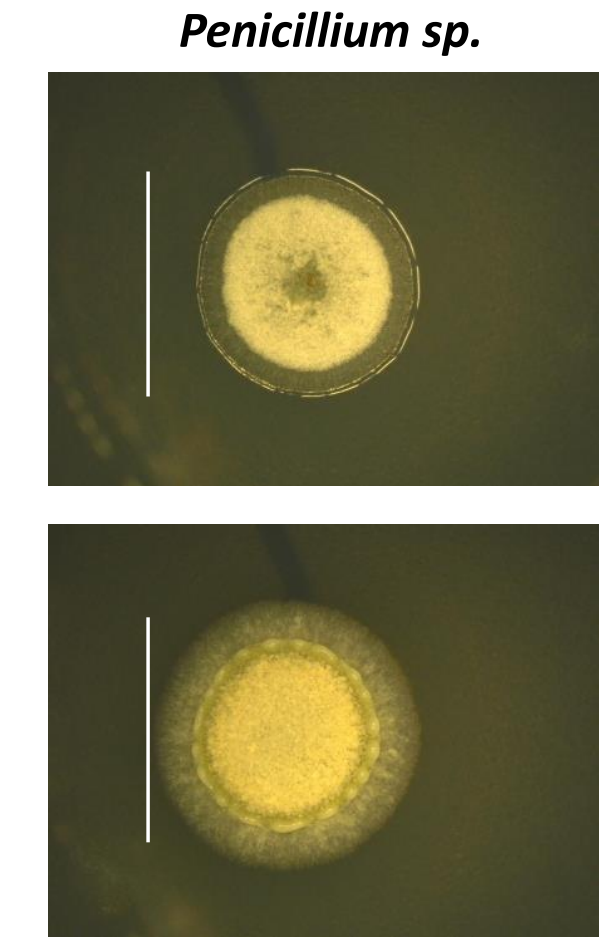

(+) P. phenazinium

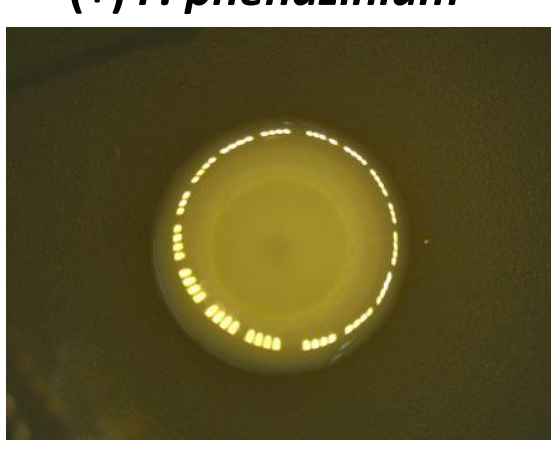

Penicillium sp.
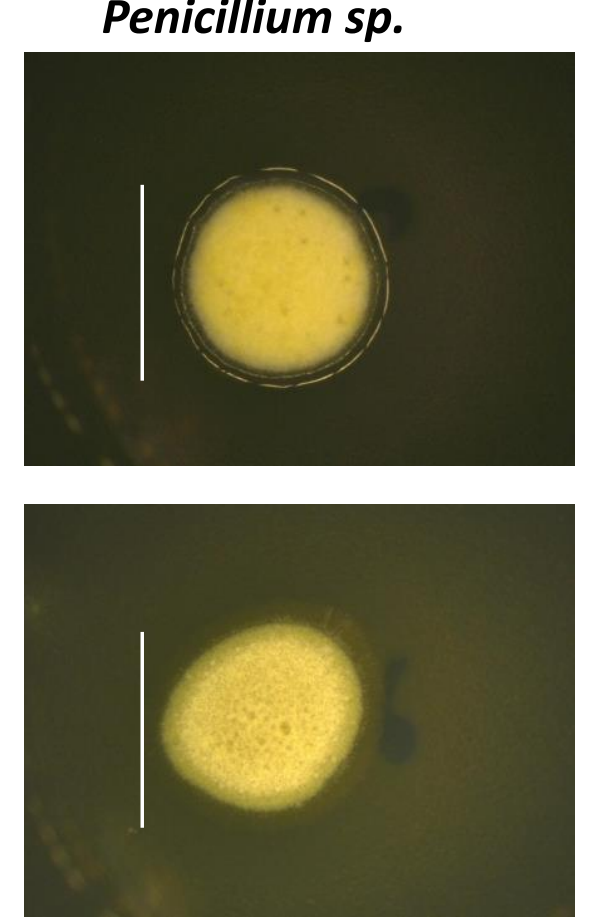

A. (-) Bacteria

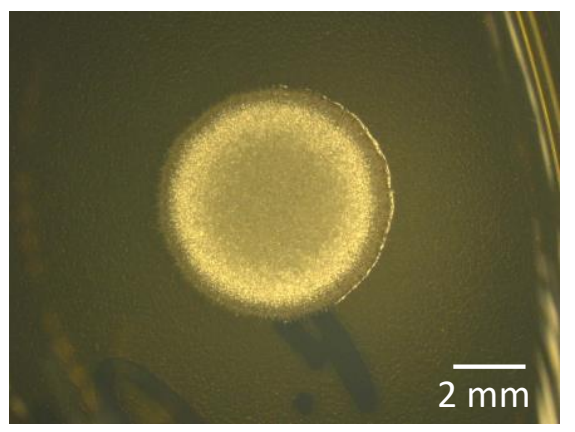

Fusarium sp.

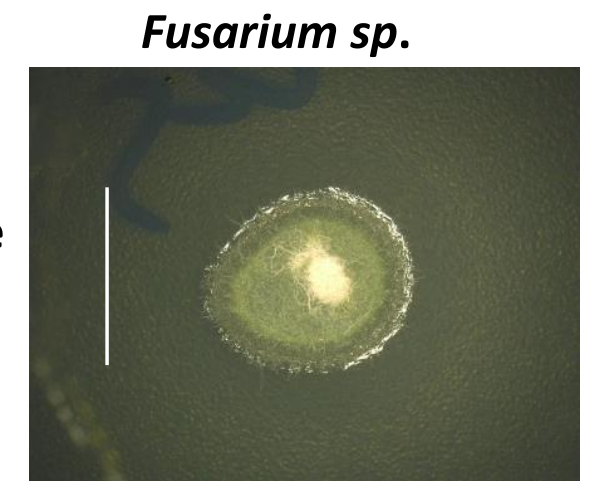

\section{Aspergillu}

B.
(+) P. unamae

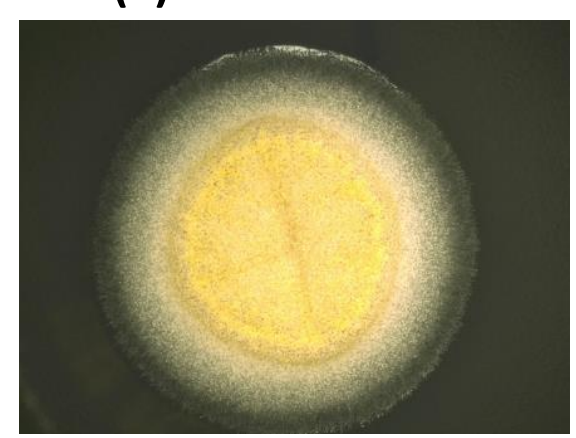

A. fumigatus

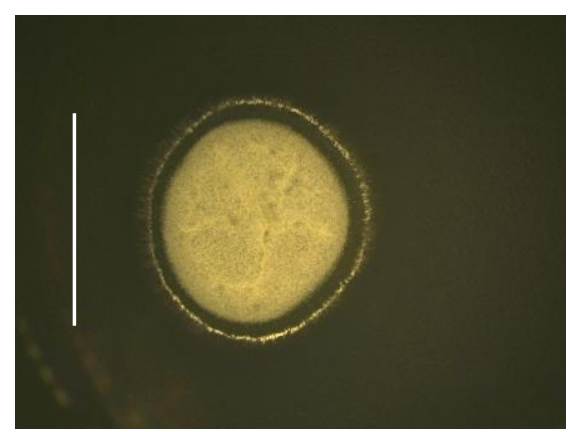

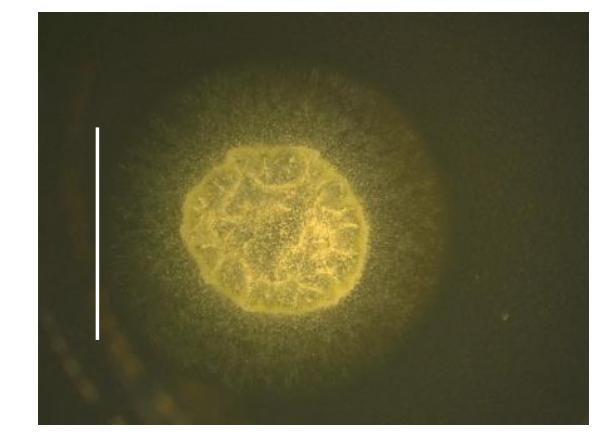

(+) P. edwinii

(+) PCA

Fungi Alone
(+) PCA

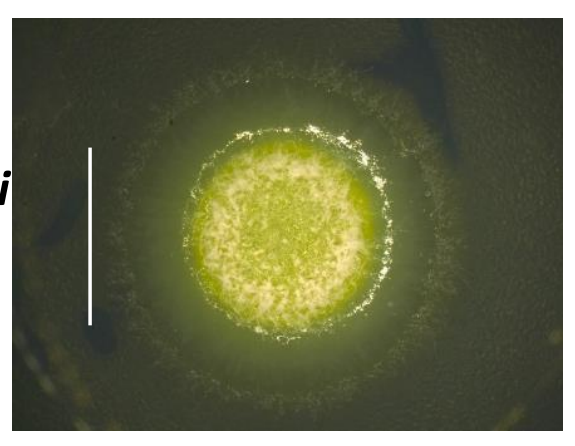

